\title{
It takes two (centrioles) to tango
}

\author{
Tomer Avidor-Reiss and Emily L Fishman \\ Department of Biological Sciences, University of Toledo, Toledo, Ohio, USA \\ Correspondence should be addressed to T Avidor-Reiss; Email: Tomer.AvidorReiss@utoledo.edu
}

\begin{abstract}
Cells that divide during embryo development require precisely two centrioles during interphase and four centrioles during mitosis. This precise number is maintained by allowing each centriole to nucleate only one centriole per cell cycle (i.e. centriole duplication). Yet, how the first cell of the embryo, the zygote, obtains two centrioles has remained a mystery in most mammals and insects. The mystery arose because the female gamete (oocyte) is thought to have no functional centrioles and the male gamete (spermatozoon) is thought to have only one functional centriole, resulting in a zygote with a single centriole. However, recent studies in fruit flies, beetles and mammals, including humans, suggest an alternative explanation: spermatozoa have a typical centriole and an atypical centriole. The sperm typical centriole has a normal structure but distinct protein composition, whereas the sperm atypical centriole is distinct in both. During fertilization, the atypical centriole is released into the zygote, nucleates a new centriole and participates in spindle pole formation. Thus, the spermatozoa's atypical centriole acts as a second centriole in the zygote. Here, we review centriole biology in general and especially in reproduction, we describe the discovery of the spermatozoon atypical centriole, and we provide an updated model for centriole inherence during sexual reproduction. While we focus on humans and other non-rodent mammals, we also provide a broader evolutionary perspective.

Reproduction (2019) 157 R33-R51
\end{abstract}

\section{Introduction}

Centrioles are subcellular organelles that are essential for many general cell processes including cellcell communication, cell division and cell motility (Bornens 2012). Defects in their structure, number and protein composition in somatic cells can lead to devastating diseases such as cancer and microcephaly (Nigg \& Holland 2018). Because of their crucial roles in these diseases, most of centriole biology focuses on characterizing them in dividing cells and targeting them for cancer treatment (Godinho \& Pellman 2014, Maniswami et al. 2018). However, centrioles also have several important, specialized roles in differentiating cells. They help direct asymmetrical divisions to drive cell differentiation (Lerit et al. 2013, Chen et al. 2016), are essential for sensory functions such as sight (Roosing et al. 2014, Zach \& Stohr 2014) and they are critical for lung function (Yan et al. 2016). These centriolar roles are well studied, but one area in need of further research is the function of centrioles during fertilization and reproduction.

It has long been accepted that centrioles are essential for fertilization, but direct experimental evidence of this is limited (Kai et al. 2015). Part of this limitation is due to a mystery involving the number of centrioles that the sperm contributes to the zygote. In the past, it was thought that the human sperm, the sole contributor of the centrioles, provided only one to the zygote
(Sathananthan et al. 1991, Kim et al. 2005, Ounjai et al. 2012, Lee et al. 2014, 2015, Fritz-Laylin \& Fulton 2016). This idea was widely accepted and included in many reviews describing reproductive centrioles in mammals (Palermo et al. 1997, Nagy 2000, Sathananthan et al. 2001, Chatzimeletiou et al. 2008, Debec et al. 2010, Chemes 2012, Ross \& Normark 2015, Patrick et al. 2017), but it also created an enigma surrounding where the zygote gets its second centriole in humans and other non-rodent mammals. The recent discovery of an atypical centriole in sperm attempts to resolve this mystery (Fishman et al. 2018).

This review centers on the formation, structure and function of the atypical centriole found in human sperm with examples from other mammals. Readers are referred to the following reviews and papers to gain information about centrioles in insects (Riparbelli et al. 2010, Fabian \& Brill 2012, Loppin et al. 2015), worms (Muller-Reichert et al. 2010, Schwarz et al. 2018) and Xenopus (Cavazza et al. 2016, Sluder 2016), as well as the role of centrioles in spindle formation (Hinchcliffe 2014, Meunier \& Vernos 2016), and the molecular mechanisms of centriole function in the zygote (Schatten \& Sun 2011, Inoue et al. 2018). To help a general audience appreciate the difference between typical and atypical centrioles, the first part of the review provides a short background on centrioles and later provides a detailed description of the unique properties of sperm centrioles. 


\section{What is a typical centriole?}

Centrioles (aka a basal body or kinetosome) are one of the core structures in an animal cell and were present in the ancestral eukaryotes about a billion years ago (Chapman et al. 2000, Hodges et al. 2010). Centrioles are made of many proteins that assemble their various substructures. While there is no convincing evidence of centriolar DNA or RNA that is independent from the nuclear DNA (Marshall \& Rosenbaum 1999), nuclear mRNA does concentrate around the centriole (Groisman et al. 2000, Lecuyer et al. 2007). Centrioles and their derived substructures form one of the largest proteinaceous structures in the cell, with a diameter of $\sim 200 \mathrm{~nm}$ and length of $\sim 500 \mathrm{~nm}$ (about half the size of a small bacteria; Fig. 1A). They have two major functions in the cell. The first is the ancestral and evolutionary conserved function: to form cilia (aka flagella) in a process called ciliogenesis (Fig. 1B). Cilia are hair-like structures that mediate cellular movement and sense the cell environment. The second main function of a centriole evolved recently in animals: the formation of the centrosome (Bornens \& Azimzadeh 2007). The centrosome is a major organizer of the microtubule cytoskeleton in animal cells. Centrosomes facilitate accurate cell division (mitosis and meiosis) and pronuclei congregation (karyogamy) and govern cell architecture and polarization (Gomes et al. 2005, Thery et al. 2006, Schatten 2012).

Centrioles have several key characteristics that allow them to execute their functions: they have an evolutionarily conserved structure and protein composition, they have dynamic accessory structures, and their number is tightly controlled (CarvalhoSantos et al. 2010, Hodges et al. 2010). Centrioles have a barrel-shaped structure and consist of a wall made of nine triplet microtubules surrounding a lumen (Winey \& O'Toole 2014). The microtubules in the triplets are known as the A, B and C tubules (Fig. 1A and $C$ ). Because microtubules are polarized, with one stable end and a growing end, the centriole is also polarized. The stable end of the centriole is called the base and the end that grows the cilium, is called the tip. When the tip grows, it forms the axoneme (the cilium core), which is an extension of the centriolar microtubules (Fig. 1B). Since ciliogenesis relies on the centriolar microtubules, and the microtubules are the most obvious substructure of the centriole, the microtubules have been deemed the defining characteristic of centrioles.

Centrioles have many substructures that associate with the microtubule wall (Fig. $1 \mathrm{~B}$ and C; Winey \& O'Toole 2014). The base of the immature centriole has a structure known as the cartwheel, which is made of a central tube with nine spokes (Guichard et al. 2018). The tip of the centriole lumen has a helix and columns that are attached to the centriole wall (Paintrand et al. 1992, Ibrahim et al. 2009). Around the centriole, there is a material referred to as the pericentriolar material (PCM). The PCM nucleates and anchors the astral microtubules, which aid in the formation and organization of the cytoskeleton. The PCM is built of concentric rings of distinct proteins (Fig. 1C; Mennella et al. 2014). In addition to the PCM, the tip of the external wall has two types of appendages: distal appendages and subdistal appendages. The subdistal appendages (aka basal foot) anchor microtubules and help position the cilium (Mazo et al. 2016). The distal appendages mediate vesicular traffic, which is needed to build the cilium membrane and to attach the centriole to the cell membrane; therefore, the distal appendages are essential for ciliogenesis (Graser et al. 2007, Sillibourne et al. 2013).

Centriole number is tightly controlled in dividing cells such that, during G1 phase, a standard cell has two centrioles (Fig. 1D). To maintain two centrioles, new centrioles form only when the DNA duplicates as the cell is preparing to divide, during $\mathrm{S}$ phase. The new centriole forms once in a cell cycle, near each preexisting centriole in a process named 'centriole duplication' (Box 1). After centriole duplication, each pair of centrioles (an old and new centriole) is recruited to one of the spindle poles during cell division, such that each daughter cell receives precisely two centrioles.

Centrioles are formed by and composed of a set of evolutionarily conserved proteins (Fig. 1E; Arquint \& Nigg 2016). Centriole formation is regulated by cell cycle kinases such as PLK1 and CDK2 (Hinchcliffe et al. 1999, Meraldi et al. 1999, Shukla et al. 2015). Centriole nucleation is initiated by two PCM proteins that surround the preexisting centriole: SPD-2/ CEP192 and Asterless/CEP152 (Blachon et al. 2008, Kim et al. 2013). These two proteins recruit Zyg-1/ PLK4, the kinase that is considered the master

\section{Box 1 Centriole duplication}

Centriole duplication is the process by which a new centriole forms near a preexisting centriole. The term centriole duplication conveys the need for preexisting centriole. However, the preexisting centriole serves merely as a platform to restrict the number of new centrioles to one new centriole per one preexisting centriole (Ross \& Normark 2015). The new centriole is not known to contain any material from the preexisting centriole. This distinction is important as the structure of preexisting centriole and the new centriole can be different. Therefore, a preexisting centriole can nucleate an atypical centriole as observed in insects (Blachon et al. 2009, Gottardo et al. 2015, Dallai et al. 2017, Fishman et al. 2017). Also, the atypical sperm centriole can nucleate a typical centriole in the zygote (Blachon et al. 2014, Uzbekov et al. 2018). 
A

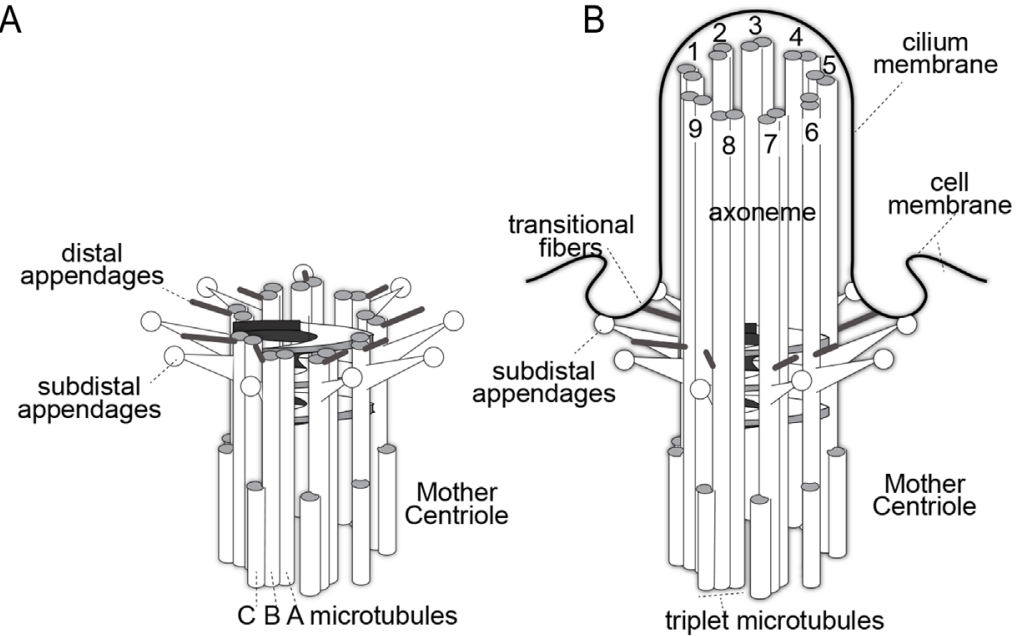

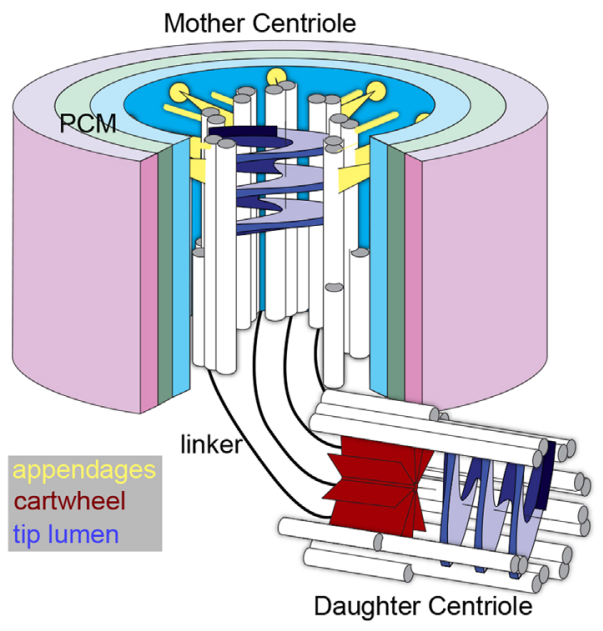

D $\begin{array}{cc}\mathrm{S} & \mathrm{G} 2 \\ \text { procentrioleformation } & \text { centrosome maturation }\end{array}$

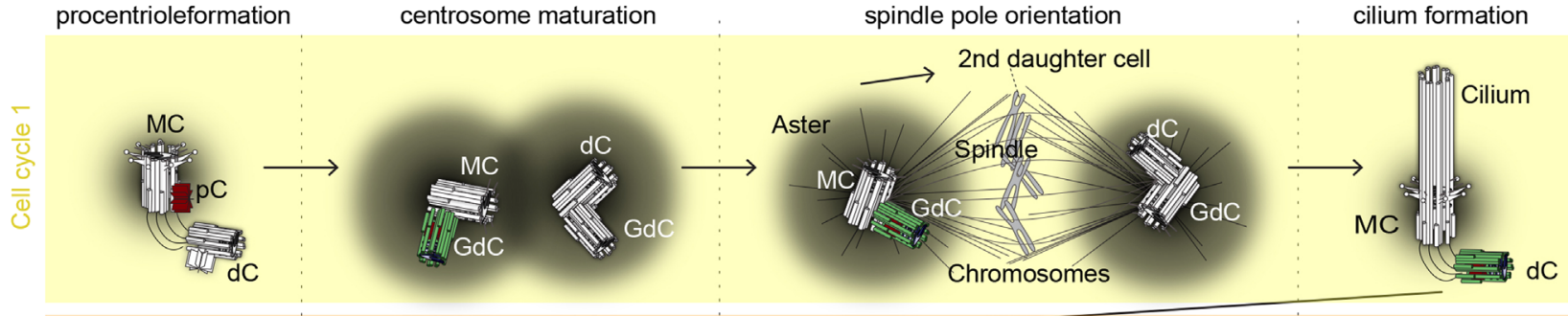
spindle pole orientation

G1

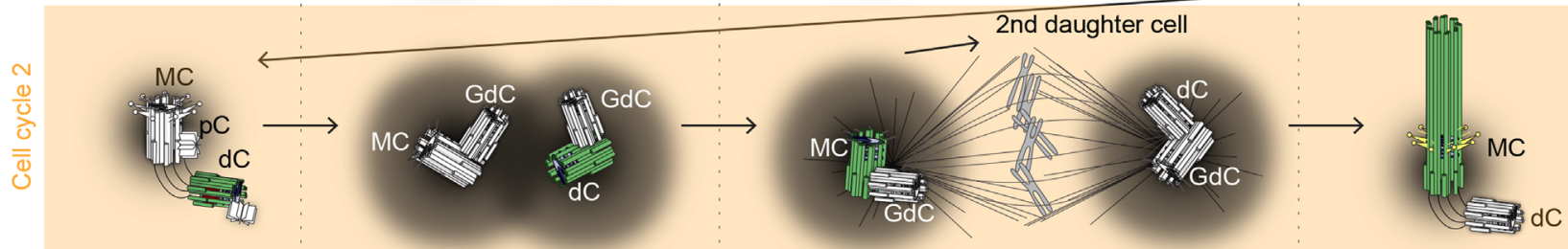

E

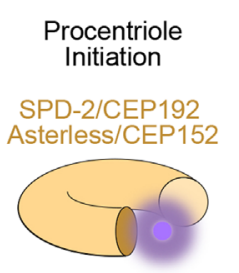

ZYG-1/PLK4

\begin{abstract}
Procentriole cartwheel formation
\end{abstract}

Zyg-1/PLK4 phosphorylation of Sas-5/Ana2/STIL
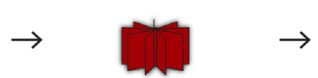

SAS6

SAS5/Ana2/STIL

\begin{abstract}
Procentriole wall formation
\end{abstract}
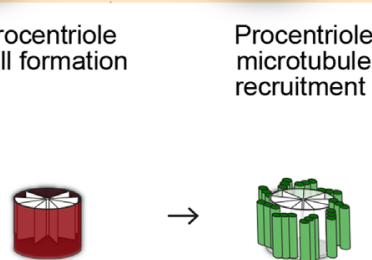

Bld10/CEP135 microtubule
recruitment
Centriole microtubule elongation \&Lumenal protein recruitment

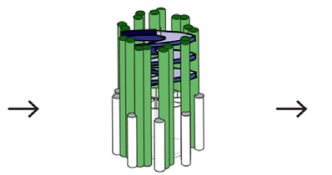

Sas-4/CPAP POC1B, POC5, CETN1/2 \& Ana1/ĆEP295

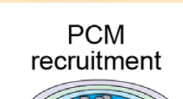

recruitment

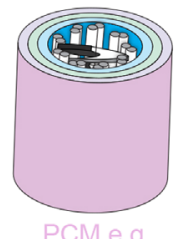

-tubulin, pericentrin

Figure 1 Typical centriole structure and function in a dividing cell. (A, B and C) Structure of the mother centriole (MC) (A), when it extends to form a cilium (B), and as part of a centrosome with a daughter centriole (dC) (C). D) The centriole through the cell cycle. A cell has four centrioles in S, G2 and M phases of the cell cycle and two centrioles in G1. It takes multiple steps throughout the two cell cycles for a centriole to mature into a mother; centriole initiation begins as a procentriole $(\mathrm{pC})$ that then develops into a granddaughter centriole (GdC), then to a dC and finally matures into a MC. The figure depicts the centriole's initiation and maturation with a single centriole highlighted in color in relation to the other centriole in grayscale. Red - cartwheel, Green - microtubules, Yellow - appendages. (E) Centriole initiation and maturation with specific attention to proteins and their functions.

regulator of centriole duplication $\left(\mathrm{O}^{\prime}\right.$ Connell et al. 2001). PLK4 phosphorylates Sas-5/Ana2/STIL that, together with SAS-6, forms the core of the centriole cartwheel (Nakazawa et al. 2007, Kratz et al. 2015, Arquint \& Nigg 2016). The periphery of the cartwheel recruits Bld10/CEP135 and Sas-4/CPAP, which assist in the formation of the centriole's microtubule wall (Hung et al. 2000, Mottier-Pavie \& Megraw 2009,
Lin et al. 2013, Zheng et al. 2014). Initially, the centriole is short (procentriole), but later, it elongates and the proteins POC1B, POC5 and CETN1/2 fill the distal lumen. Then, Ana1/CEP295 is recruited and mediates the recruitment of PCM proteins to the centriole (Salisbury et al. 2002, Azimzadeh et al. 2009, Keller et al. 2009, Pearson et al. 2009, Izquierdo et al. 2014, Chang et al. 2016, Tsuchiya et al. 2016) 


\section{Box 2 Spermatogenesis cell types}

Spermatozoa are formed during spermatogenesis, a differentiation process that is divided into several cell types (Fig. 2A, B, C, D and E). The spermatogonia are stem cells that undergo several mitotic divisions to amplify the number of sperm in mammals (Fig. 2D). The spermatogonia then differentiate and transform into spermatocytes (Fig. 2B and C) that enter into meiosis to generate haploid cells known as spermatids. The spermatids undergo a dramatic cellular 'metamorphosis' from round cells to elongated and streamlined cells called spermatozoa (Fig. 2D). The testicular spermatozoa are the final differentiated cells produced by spermatogenesis, but they are not fully mature and are immotile. The testicular spermatozoa enter the epididymis, develop motility and mature as they progress through the caput (Sullivan \& Mieusset 2016). Later, they proceed along the corpus and are finally stored in the cauda until transportation through the vas deferens and ejaculation. Spermatozoa continue to change after they are ejaculated as they travel along the female reproductive tract in a process called capacitation (Gervasi \& Visconti 2016).

Centrioles are dynamic structures that change during the cell cycle (Bornens 2012; Fig. 1D). These changes can be divided into two types: changes that occur during centriole formation and are complete within two cell cycles and changes that occur as the mature centriole oscillates between functional states for the remainder of its life. Centriole formation starts in $\mathrm{S}$ phase as a short procentriole forms attached to the preexisting centriole wall (referred to as engaged). Then, the procentriole elongates to form a daughter centriole in $\mathrm{G} 2$ and forms the luminal helix and columns. Next, the daughter centriole loses its cartwheel and disengages from its mother centriole in $M$ phase. Later, it nucleates a new procentriole in the second $\mathrm{S}$ phase. The centriole then recruits a large amount of PCM and functions as a centrosome during the second G2 phase, forming one of the spindle poles during its second $\mathrm{M}$ phase. Finally, the fully mature centriole forms its appendages and its first cilium in the second G1 phase. After maturation, the centriole continually oscillates between four functional states during the cell cycle: (1) forming a procentriole in $\mathrm{S}$ phase; (2) expanding PCM and reducing appendage size in G2 and M phases; (3) localizing to the spindle pole to orient the spindle in $M$ phase and (4) reducing PCM size, re-growing the appendages, anchoring to the cell membrane and forming the cilium in G1 phase (Palazzo et al. 2000, Garcia \& Reiter 2016).

The description above refers to the typical centriole and its behavior in a cell that continuously grows and divides, such as animal stem cells. However, centrioles can be dramatically different in one or more of their characteristics in differentiated cells. For example, many types of white blood cells do not form a cilium in G1 and in cytotoxic $\mathrm{T}$ lymphocytes the centriole forms a centrosome that anchors to the cell membrane but does not extend to form a cilium (Stinchcombe et al. 2015). Multi-ciliated epithelial cells produce dozens of centrioles instead of only one centriole per preexisting centriole via a specialized structure, the deuterosome (Brooks \& Wallingford 2014). In several cell types, like muscle cells and oocytes, the centrioles are thought to be eliminated during differentiation (Connolly et al. 1986, Manandhar et al. 2005, Pimenta-Marques et al. 2016). Like other differentiated cell types, sperm cells exhibit many atypical properties and are discussed in further detail below.

\section{What are the unique characteristics of sperm centrioles?}

In general, centrioles in early spermatogenesis (those of spermatogonia and spermatocytes) are similar to those found in normal cells, whereas those in late spermatogenesis (those of elongated spermatids) are different (Box 2).

Spermatogonia have two centrioles that duplicate to become four centrioles each time the cell prepares to divide (Fig. 2A). The centriole cycle of spermatogonia is like that of other stem cells, but they lack primary cilia in G1 (Nygaard et al. 2015).

Spermatocytes are formed when a spermatogonium duplicates its genome (from two sets of chromosomes, ' $2 \mathrm{~N}^{\prime}$, to four sets of chromosomes, ' $4 \mathrm{~N}^{\prime}$ ) and centrioles (from two centrioles to four), and enters meiosis. There are two types of spermatocytes, primary and secondary. Primary spermatocytes have a duplicated genome $(4 \mathrm{~N})$ and four centrioles (Fig. 2B). Primary spermatocytes then divide by meiosis I, resulting in two secondary spermatocytes, each having two sets of chromosomes $(2 \mathrm{~N})$ and two centrioles. In the secondary spermatocytes, these two centrioles duplicate to form four centrioles prior to the second meiotic division (Rattner 1972; Fig. 2C). Unlike in other cells, centriole formation in mammalian secondary spermatocytes takes place in the absence of genome duplication, generating

\section{Box 3 Spermatozoon morphology}

A spermatozoon is composed of a head and a tail that contains the centrioles and cilium (Fig. 2E). The tail is divided into four parts: the connecting piece (also known as the sperm neck), which houses the centrioles and specialized PCM material known as the striated columns and capitulum; the midpiece that houses part of the axoneme and the mitochondria; the principal piece, which houses the part of the axoneme without mitochondria and the terminal piece, which lacks both the axoneme and mitochondria (Werner \& Simmons 2008, Lindemann \& Lesich 2016, Mortimer 2018). 

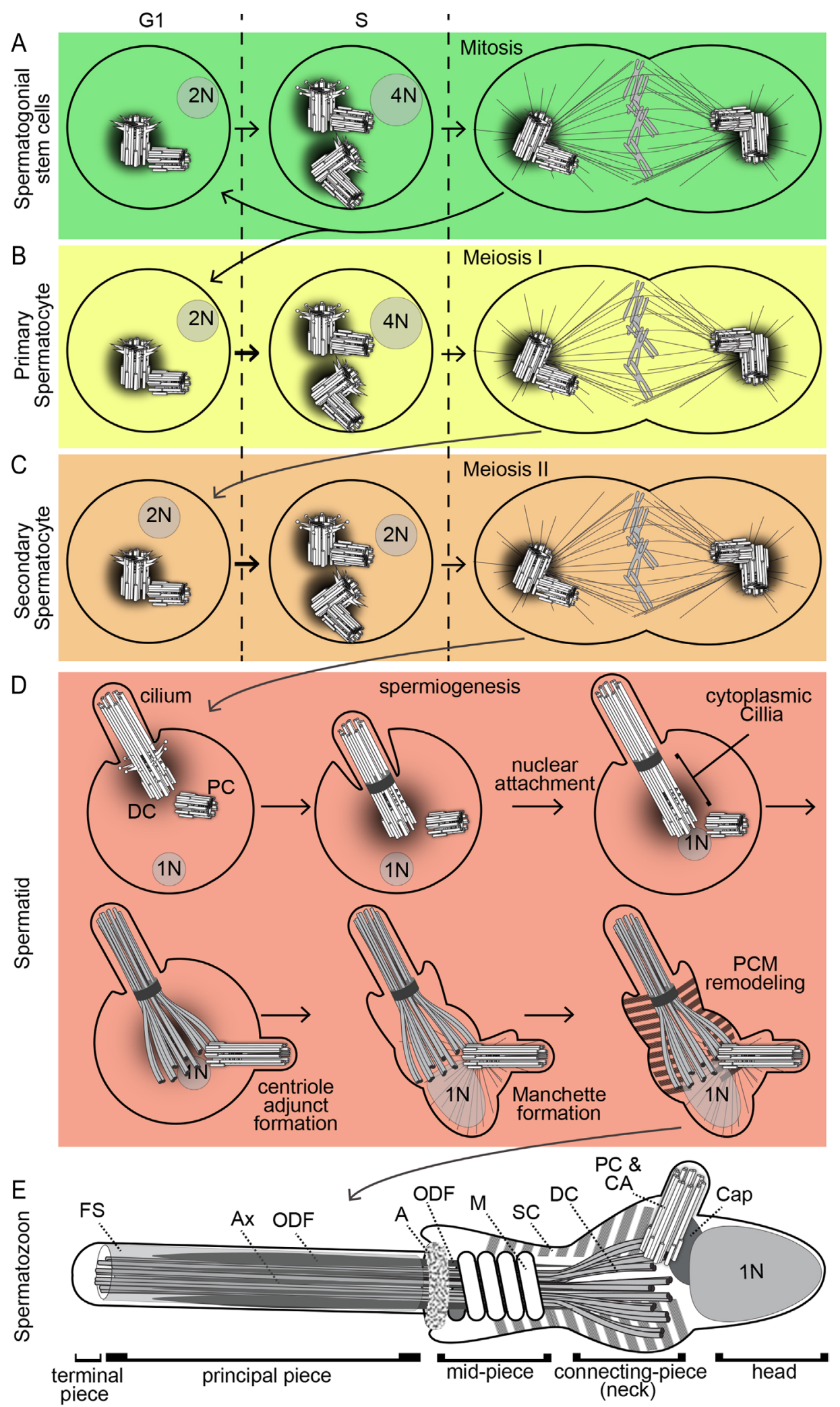

Figure 2 The centriole during human spermatogenesis and in the spermatozoon. The formation and function of a centriole during the differentiation of a spermatogonial stem cell (A), primary spermatocyte (B), secondary spermatocyte (C), spermatid (D), to a spermatozoon (E). $1 \mathrm{~N}, 2 \mathrm{~N}$ and $4 \mathrm{~N}$ : number of chromosome ploidy in the nucleus; G1, S, M: cell cycle phases. The pictures are not to scale. $\mathrm{A}$, annulus; $\mathrm{Ax}$, axoneme; CA, centriolar adjunct; Cap, capitulum; DC, distal centriole; FS, fibrous sheath; M, mitochondrion; ODF, outer dense fibers; PC, proximal centriole; SC, striated column. 
a cell that has four centrioles but only two sets of chromosomes $(2 \mathrm{~N})$. This is an uncommon situation that is poorly understood and deserves more attention, but may resemble the centriole amplification without DNA duplication that occurs during the differentiation of multi-ciliated cells (Loukil et al. 2017). Interestingly, the centrioles of mammalian spermatocytes do not form a cilium, but the spermatocyte centriole in insects forms a cilium that is present throughout meiosis I and meiosis II (Riparbelli et al. 2012, Basiri et al. 2014).

Haploid spermatids are formed when the secondary spermatocytes divide by meiosis II. Spermatids undergo dramatic morphological changes throughout their development to produce spermatozoa (Box 3) (Fig. 2D); spermatids and spermatozoa do not undergo any further divisions. Early spermatids (round spermatids) consist of one set of chromosomes $(1 \mathrm{~N})$ and a centrosome with two centrioles surrounded by PCM. In spermatids, the mother centriole is renamed the distal centriole (DC) because it occupies distal location relative to the nucleus. The daughter centriole is named as proximal centriole (PC) because it resides proximal to the nucleus.

Mammalian centrioles in early spermatid stages are similar to typical G1 centrioles. The early spermatid centrioles attach to the cell membrane and form a cilium (Fig. 2D). However, in later stages, centriole behavior deviates in five important ways:

(i) centriole attachment to the nucleus - The two early spermatid centrioles migrate from the cell periphery to the interior where they attach to the nucleus via a specialized structure named the Head-Tail Coupling Apparatus (Liska et al. 2009). This type of centriolar attachment is unique to sperm cells and is poorly understood. Maintaining the centrosome near the nucleus is important in several cellular contexts and is mediated by the LINC complexes formed by SUN and KASH proteins (Starr \& Fridolfsson 2010, Kracklauer et al. 2013). Recently, SUN proteins were found to anchor the tail to the head in humans and Drosophila (Gob et al. 2010, Kracklauer et al. 2010, Shang et al. 2017).

(ii) transition zone migration to form a cytosolic cilium - In most cells, the cilium is separated from the cytosol and the mitochondria by a gate called the transition zone, which is found at the centriolecilium junction (Malicki \& Avidor-Reiss 2014). However, in mammals, the part of the axoneme that is close to the centriole is exposed to the cytoplasm and associated with mitochondria, forming the midpiece of the sperm tail. This exposure of the axoneme to the cytosol is unique to sperm cells and forms a specialized type of cilium named the cytosolic cilia (Avidor-Reiss \& Leroux 2015). This process is mediated by the migration of the transition zone (also known as the annulus) along the axoneme (Toure et al. 2011, Basiri et al. 2014,
Avidor-Reiss et al. 2017). The migration of the transition zone that forms the midpiece requires more research. Interestingly, the midpiece size seems to change specifically with the level of sperm competition; for instance, the midpiece is shorter in deer mice, which are monogamous and have little sperm competition (Fisher et al. 2016). In established lines of house mice, sperm with a larger midpiece have a faster swimming velocity (Firman \& Simmons 2010). These differences in midpiece size highlight the important role sexual evolutionary pressure plays in shaping the spermatozoon (Gomendio \& Roldan 1991, Lupold \& Pitnick 2018).

(iii) centriolar adjunct formation - During spermiogenesis, the PC microtubules elongate to form an extension called the centriolar adjunct. The adjunct, while visually similar to the axoneme is unexpected because the PC is the analog of the immature daughter centriole; this function is usually restricted to the elder, mature, mother centriole. The adjunct resembles a cytoplasmic cilium in that it is exposed to the cytoplasm, and not encapsulated by the cell membrane. The adjunct is transient in most mammals, including Rhesus, but is present in ejaculated human spermatozoa (Manandhar \& Schatten 2000). The presence of the adjunct in the spermatozoa was proposed to be one of three human spermatozoa characteristics that point to its relative immaturity (Zamboni \& Stefanini 1971). The centriolar adjunct in mammals should not be confused with the insect sperm's centriole adjunct, which is a specialized PCM that associates with the DC (Dallai et al. 2016).

(iv) manchette formation - The manchette is a transient microtubule-based structure that surrounds the spermatid and helps in reshaping the head during spermiogenesis. The mechanism of manchette microtubule nucleation is unclear; one model is that the sperm centrioles or centriole adjunct are mediating manchette nucleation (for review, see O'Donnell \& O'Bryan 2014, Lehti \& Sironen 2016). This model has been supported by the finding that the daughter centriolar protein CNTROB resides in the capitulum, the PCM structure near the PC and is also essential to maintain the head/tail attachment (Liska et al. 2009).

(v) centriole remodeling (aka centrosome reduction) - The fifth deviation is that the centrosome and its centriole are remodeled (or reduced) to have atypical structure and composition (Sathananthan et al. 1991, Fishman et al. 2018). This is discussed in detailed below.

\section{What are centrosome reduction and centrosome remodeling?}

Historically the term 'reduction' is used to describe the decrease in cell components in the gametes prior 
to fertilization. This reduction forms gametes that complement each other, such that their fusion will result in a single cell that has appropriate quantities of organelles, chromosomes and cytoplasm. For example, during the formation of the spermatid and oocyte, the nuclear content of each cell is reduced to one set of chromosomes $(1 \mathrm{~N})$ so that upon fertilization, the resulting zygote has two sets of chromosomes $(2 \mathrm{~N})$. A similar reduction is expected for centrioles because a somatic dividing cell must have precisely two centrioles. However, the reduction pattern observed in centrioles is different from that in the genome. The oocyte loses both its centrioles so that the oocyte's centriolar contribution will be compatible with that of the sperm and will result in a zygote with exactly two centrioles (Connolly et al. 1986, Schatten 1994, Manandhar et al. 2005, PimentaMarques et al. 2016).

Another form of centrosome reduction takes place in the sperm. Originally, it was thought that non-rodent mammalian sperm loses one of its centrioles as a part of the centrosome reduction process (Sathananthan et al. 1991). This idea was based on the observation that the sperm loses PCM and centriolar proteins as a part of centrosome reduction, and it was concluded that the sperm was left without a recognizable PCM or centriole. However, it was recently discovered that the sperm maintains both of its centrioles, although one of them is remodeled into an atypical structure and composition. During this remodeling process, specialized sperm PCM structures replace the typical PCM (Fig. 2D; Fawcett \& Phillips 1969). The specialized PCM structures are called the striated columns and the capitulum; they are thought to have a structural role in connecting the sperm head to the tail. Their function is poorly understood, but it is thought that they are involved in sperm tail beating (Iwashita \& Oura 1980, Ounjai et al. 2012).

Complimentary to the sperm, the oocyte lacks centrioles, but has PCM proteins diffused in the cytosol (Severson et al. 2016). Once the sperm and the oocyte fuse during fertilization, the sperm centrioles recruit maternal PCM proteins to form the zygote centrosomes. This recruitment is referred to as centrosome reconstitution (Schatten et al. 1986).

Because the sperm's centrosome is not lost, but rather remodeled, the term centrosome remodeling has been adopted to encompass centrosome reduction, as well as structural changes, protein enrichment and redistribution in the centrioles, striated columns and capitulum. During centrosome remodeling, many PCM proteins are reduced and the PC loses some proteins typically found in a centriole while maintaining its overall barrelshaped structure. The DC undergoes several changes; it loses proteins typically found in a centriole, but some centriolar proteins are also enriched. The PCM and centriolar proteins that remain are redistributed within the DC, striated columns, and capitulum. Additionally, the DC loses its barrel shape and becomes splayed and flattened.

Altogether, in mammals, the early spermatid has two typical centrioles (the DC and PC) (Fig. 2D). During spermatid differentiation, the striated columns and capitulum replace the typical PCM, the DC's structure and composition change and the PC's protein composition is modified. This change generates a spermatozoon where all the centrosome components (PC, DC and PCM) are modified at least in one way, leading to the hypothesis that the whole sperm centrosome is remodeled but not eliminated (Fig. 2E).

\section{What is the structure and protein composition of the remodeled DC, PC and PCM?}

In human spermatozoa, the protein composition of the remodeled sperm centrosome is distinct from that of a typical centrosome (Fig. 3). The remodeling process includes the loss and enrichment of some centrosomal proteins, the appearance of sperm-specific proteins, the formation of protein bars in the $\mathrm{DC}$, and the redistribution of centrosomal proteins between the PC, DC and PCM. The PCM transforms into the specialized structures, the capitulum and striated columns. The capitulum and striated columns contain sperm-specific proteins such as SPATA6 (Yuan et al. 2015), SPAG4 (Shao et al. 1999) and speriolin (Goto et al. 2010). The typical PCM proteins $\gamma$-tubulin, PCNT, CEP152 and CEP192 are missing, and the striated columns and capitulum include the centriole proteins RTTN and CEP295. The PC retains its typical centriole structure and some centriolar proteins, such as CEP135, CEP120 and CEP76. Hoverer, the PC is missing the centriole cartwheel protein SAS-6, as well as centriole wall proteins CNTROB and RTTN.

The DC develops an atypical centriole structure and has a subset of centriole proteins. The centriole microtubules are doublets instead of triplets. The doublets are disconnected, possibly due to the loss of the protein linker between adjacent microtubules. The disconnected doublet-microtubules splay out, forming an oblong cone. Inside the cone, bars of proteins are wedged along the microtubules. The DC is missing the centriole wall proteins CEP135, CEP120, RTTN and CEP295, centriolar tip proteins CP110 and CEP76 and the appendage proteins CEP89 and CEP164. Instead, the DC has rods made of centriolar lumen proteins CETN1/2, POC5 and POC1B. The bars appear to be capped at their base by the PCM protein CEP63. The centriolar protein CPAP associates with the DC. Interestingly, the transition zone protein CEP290 appears to form a ring in the junction between the DC and the axoneme. How the typical centriole changes into an atypical centriole is unknown, and identifying the molecular mechanism underlying this change is an important future direction. 


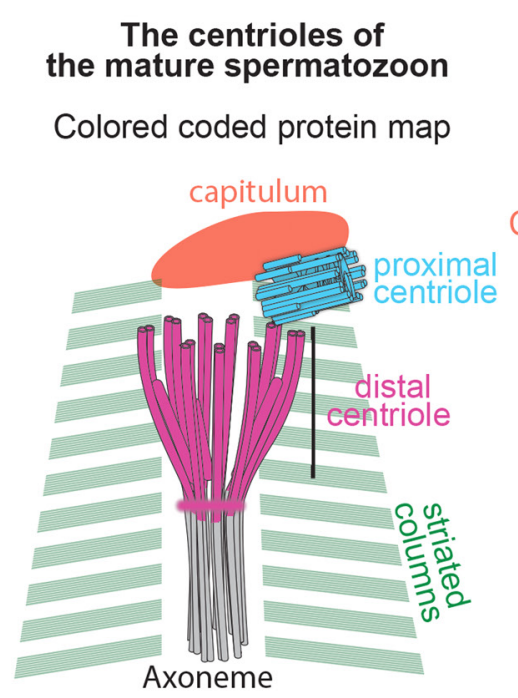

\begin{tabular}{|c|c|c|c|c|c|}
\hline $\begin{array}{l}\text { PCM } \\
\text { CEP63 }\end{array}$ & $\begin{array}{l}\text { Distal } \\
\text { lumen }\end{array}$ & $\begin{array}{c}\text { Centriole } \\
\text { wall }\end{array}$ & $\begin{array}{c}\text { DAP } \\
\text { CEP164 }\end{array}$ & $\begin{array}{l}\text { sDAP } \\
\text { ODF2 }\end{array}$ & $\begin{array}{c}\text { other } \\
\text { centrosomal }\end{array}$ \\
\hline CEP57 & CETN1/2 & $\alpha$-Tubulin & CEP89 & NIN & CEP44 \\
\hline CEP126 & POC5 & $\beta$-Tubulin & PCM1 & CEP170 & FGFR1OP \\
\hline SSX2IP & POC1B & CPAP & CEP83 & CCDC68 & CEP78 \\
\hline CDK5RAP2 & SFI1 & CEP135 & SCLT1 & CCDC120 & POC18 \\
\hline PCNT & POC1A & CEP120 & FBF1 & CEP128 & ATF-5 \\
\hline CEP192 & OFD1 & CNTROB & CLERC & & CEP131 \\
\hline CEP152 & & RTTN & TSGA14 & & CETN3 \\
\hline$\gamma$-tubulin & & CEP295 & WDR16 & & SPICE1 \\
\hline CEP41 & & e-tubulin & DCNT & & CEP104 \\
\hline PCNT & & $\delta$-tubulin & ODF2 & & CEP128 \\
\hline PLK1 & $\begin{array}{l}\text { Linker } \\
\text { Rootletin }\end{array}$ & $\underset{\text { tip }}{\text { Centriole }}$ & $\begin{array}{l}\text { CEP170 } \\
\text { NINI }\end{array}$ & Spe & $\begin{array}{l}\text { CEP19 } \\
\text { CEP97 }\end{array}$ \\
\hline Cartwheel & C-Nap1 & CEP290 & OFIP & proteins & NA14/DIP13 \\
\hline SAS-6 & Nek2 & CP110 & C2CD3 & SPATA6 & TSGA10 \\
\hline STIL & PP1 & CEP76 & CCDC41 & SPAG4 & CEP70 \\
\hline PLK4 & LLRC45 & Cep97 & & Speriolin & LGALS3BP \\
\hline
\end{tabular}

Figure 3 Map of centrosome proteins in the spermatozoa. Proteins are grouped based on their location in a typical centriole (linker, cartwheel, centriole wall, etc.). Centriole protein names are color coded based on their location in the sperm remodeled centriole (capitulum, striated columns, PC, distal centriole (DC) and axoneme). Purple italic font marks proteins that were investigated, but are absent from the remodeled centriole. Gray font marks proteins that were not tested in the spermatozoon. Bi-color proteins are present in two locations corresponding to the color schema in the sperm centriole drawing.

\section{How and when does the DC remodeling take place in various mammals?}

The DC is remodeled in all mammals studied to date, suggesting that it is an evolutionarily conserved process that varies only in degrees of completion (Box 4) (Fig. 4; Fawcett \& Phillips 1969, Gordon 1972, Manandhar et al. 1998). The DC has unique properties in various groups and appears to progressively change during evolution to make the DC more atypical in some groups. In amniotes like snakes, the DC becomes atypical by having a central pair of microtubules in the lumen of the barrel-shaped DC, much like the central pair of an axoneme. In bovine, the DC's microtubules splay and large DC rods are present (1.5-to -2-fold larger in length and width than human spermatozoa's DC, based on super resolution microscopy). In humans, the DC rods are smaller, and in mice, the DC rods and microtubules appear to be absent (Manandhar et al. 1998, Fishman et al. 2018) and our unpublished data). More information on the evolution of sperm centrioles can be found in (Avidor-Reiss 2018). Below, we will focus on the changes in centriole microtubules and the appearance of bars/rods in the mammalian DC.

\section{Box 4 Models of centriole inheritance during animal sexual reproduction}

Unlike a general cell that has two functional centrioles, the oocyte has inactivated centrioles or no centrioles (Pimenta-Marques et al. 2016, Verlhac 2016). Therefore, it is thought that the embryo's first centrioles are paternal, originating from the sperm centrioles (Fig. 5). Indeed, spermatids and spermatozoa of many animal groups (e.g., frogs, C. elegans and sea urchin) have two typical centrioles in the spermatozoa (PC and DC) (Fig. 5A; Houliston \& Elinson 1991). In the zygotes of these animals, each of the two typical sperm centrioles duplicate to form new typical centrioles (the zygotic daughter centriole); each of the centriole pairs form one of the spindle poles. However, the spermatozoa of most mammals, including humans (Fig. 5B) and insects (Fig. 5C) have only one centriole with a typical structure (although with atypical protein composition) and the other centriole has an atypical structure and an atypical protein composition (Khire et al. 2016, Fishman et al. 2018). The atypical centriole originates as a typical centriole in spermatids and only becomes atypical after a remodeling process (Fig. 5B). The mammalian and insect DC remains attached to the axoneme throughout zygotic development (Riparbelli \& Callaini 2010, Fishman et al. 2018). Both centrioles form a zygotic daughter centriole and one of the spindle poles. Fly spermatozoa also have one typical (the DC) and one atypical centriole called the proximal centriole-like (PCL) structure, which lacks microtubules altogether but is still functional. However, unlike the mammalian atypical centriole, the PCL is formed in the spermatid and is, from conception, atypical (Fig. 5C). The PCL structure is further modified by centrosome remodeling, and the PCL loses its wall. In rodents (e.g., mice and rat), the centrioles are thought to be absent in the spermatozoa (Fig. 5D; Manandhar et al. 1999, Manandhar et al. 2005, Simerly et al. 2016). Therefore, mice zygotes are thought to have no centrioles. It was proposed that centrioles form in the mouse embryo de novo at the 32/64-cell stage (Courtois et al. 2012), but de novo centriole formation is error prone and therefore unlikely (Wang et al. 2015). However, it is possible that the centrioles of murine spermatozoa are even more atypical than those of other mammals, potentially explaining why they are yet to be detected. 


\section{The DC microtubules}

In mammals, the dogma was that centrosome reduction degenerates the DC, leaving a nonfunctional remnant in the spermatozoa near the PC. Consistent with this idea, most conventional electron microscopy studies found that the expected location of the DC lacks centriolar microtubules, has remnant microtubules or contains only the axoneme's central pair (Manandhar \& Schatten 2000). In non-rodent mammals, Manandhar and Schatten found that epididymal and ejaculated spermatozoa had only a PC with a typical barrel-shaped structure with nine triplet microtubules. In contrast, two studies report that DC microtubules are present, albeit with highly modified organization, in the spermatozoa of humans, monkeys and rabbits (Zamboni \& Stefanini 1971, Fishman et al. 2018). Together, these studies find that (1) the axoneme central microtubule pair extends through the remodeled DC, (2) the triplet microtubules become doublets, (3) the link found between the microtubule triplets that holds them tightly together is absent, and the microtubule doublets splay out and (4) the 8-9 doublets adopt a flattened cone shape. The presence of DC microtubules is verified by immunostaining microscopy against tubulin and acetylated tubulin in humans, suggesting that the microtubules are acetylated. Similar immunostaining is observed in other mammals such as bovine, monkeys, pigs and rabbits (our unpublished data), suggesting atypical DC microtubule organization is a general property of mammals.

\section{The DC bars}

Centrosome remodeling results in the appearance of electron-dense bars in the lumen of the DC visible using electron microscopy and rod-shaped aggregates of centrosomal proteins visible using immunofluorescent microscopy. These bars and rods are unique to the elongated spermatids and spermatozoa and are not found in other centrioles. While it is a logical expectation that the electron-dense bars and centriolar protein rods are the same structure, this needs verification. Below, we describe the distinct observations of the DC's bars and rods in various mammalian orders.

\section{Primates/human}

In human spermatozoon, high-pressure freezing, freeze substitution electron microscopy detects the DC bars (Fishman et al. 2018). Three centriolar proteins (CETN1/2, POC1B and POC5) exhibit a rod shape in the DC by super resolution microscopy. Both the human DC bars and rods are smaller than those observed in bovine (Fig. 4).

\section{Laurasiatheria -ungulates (hoofed animals)}

There are two ultrastructural studies describing the presence of two electron-dense bars in the mature spermatozoa of bovine and boar. One study used classical, chemically fixed, electron microscopy in boar spermatozoa (Nicander \& Bane 1962). The other study uses electron cryotomography to generate a 3D structure

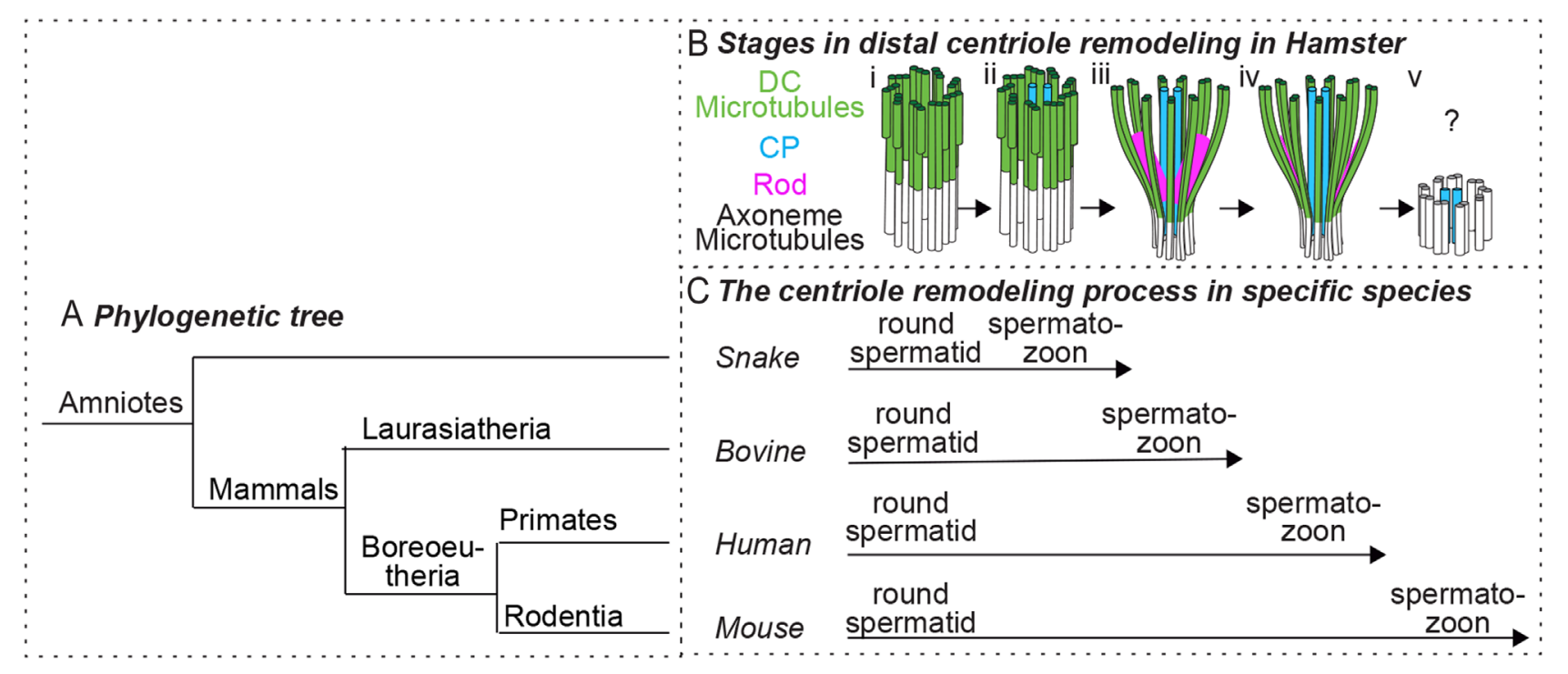

Figure 4 Various animal species exhibit some or all steps in DC remodeling. (A) Phylogenetic tree depicting the relative evolutionary position of snake, bovine, human and mouse. (B) Stages in DC remodeling during spermiogenesis of hamster. The centriole is penetrated by the central pair $(\mathrm{CP})$, and then has splayed microtubules, then robust rods appear, then they reduce in size and finally, the microtubules and rods disappear. Whether there is a very atypical DC structure or no DC at all at the end of the remodeling is unknown. (C) The associated stages of DC remodeling in spermiogenesis of four animal species. The DC is progressively more modified in snake, bovine, human and mouse. The DC of snake spermatozoon is penetrated by the $\mathrm{CP}$ (Bii). The DC of bovine spermatozoa is penetrated by the CP, and also has splayed microtubules and robust rods (Biii). The DC of human spermatozoon is penetrated by the center pair, has splayed microtubules and the rods are present, but are of reduced size (Biv). The mouse appears to have no DC (Bv). 
of the connecting piece in bovine sperm (Ounjai et al. 2012). Super resolution microscopy of the centriolar protein POC5 exhibits a rod-like shape in the DC with two major rods and one minor rod (Fishman et al. 2018). These studies suggest that the DC rods in ungulate spermatozoa are more robust than in humans (Fig. 4).

\section{Rodents}

In rodents, electron-dense DC bars are observed transiently during spermiogenesis, but not in spermatozoa (Fig. 4). The observation of the DC bars during spermiogenesis, in parallel to the other changes of the DC, is interesting as it provides insight into the process of DC rod formation. In guinea pigs, chinchilla and Chinese hamsters, the DC undergoes a dynamic multi-step remodeling process (Fawcett \& Phillips 1969, Gordon 1972; Fig. 4B). Initially, like in typical cilia, the DC is connected to an axoneme, which is made of nine axonemal doublets, the two central microtubules (Fig. 4Bi). Then, the two central microtubules of the axoneme extend into the centriole lumen (Fig. 4Bii), the DC doublet-microtubules start to spread out, electron-dense bars form in the DC lumen near the two central microtubules, the DC's nine triplet microtubules become doublets and separate from each other slightly (Fig. 4Biii). The DC doublet-microtubules continue to spread out and the bars are reduced in size. Finally, in the testicular spermatozoon, the DC bars and microtubules disappear.

Gordon (1972) found that the electron-dense bars are surrounded by electron light material, referred to as 'internal cylinders.' This study used an uncommon staining protocol that includes exposure to ethanolic phosphotungstic acid after the glutaraldehyde fixation and acetylation, which may have allowed for this observation. Altogether, it appears that the electrondense bars in the DC lumen are present transiently during mid-spermiogenesis. It is important to test if these bars have similar composition to the rods observed in other mammals, as this would support using mice spermiogenesis as a model for DC remodeling.

\section{Basal tetrapod}

Insight from a phylogenetic study of tetrapods may shed light on the origin of the DC bars. It is thought that the DC of the ancestral tetrapod had several novel traits (Healy \& Jamieson 1994, Jamieson 2014). The DC was very long (several micrometers), extending all along the sperm midpiece. Each of the nine DC microtubule groups was made of two complete microtubules (the A and B microtubules) and an incomplete C-microtubule. The DC had the two central microtubules normally found only in the axoneme's center, which is an atypical property for centrioles. The two central microtubules associate with electron-dense material; this electron-dense material may be the ancestor of the DC bars. Since the electron-dense material associates with the two central microtubules, it is possible that the two central microtubules have a role in the formation of the bar structure. Therefore, studying basal tetrapod DC formation may provide critical insight to the evolution of DC remodeling.

\section{Is the mouse a good model for human centriole inheritance and function?}

One perplexing aspect of the recent discovery of the human atypical DC is its apparent disagreement with the current literature in mice, rats and other rodents. Rodents appear to lack sperm centrioles due to centrosome reduction (Schatten et al. 1985, Manandhar et al. 1998). Furthermore, the centrosomes and the two large asters that are present in the zygote of humans and other nonrodent mammals are not present in the mouse zygote. Instead, like in the oocyte, the mouse zygote forms many mini asters that participate in the formation of an acentriolar spindle (Schatten et al. 1985, Calarco 2000, Coelho et al. 2013, Clift \& Schuh 2015). This spindle is unlike the pointy spindle of non-rodent mammals in that it is barrel-shaped, with flat poles. These flat spindle poles recruit centrosomal proteins despite their lack of typical centrioles (Coelho et al. 2013). Furthermore, while the DC-attached base of the human and bovine sperm tail localizes to a spindle pole, the mouse's sperm tail does not localize to the spindle pole (Simerly et al. 1995b). Therefore, if mouse sperm contains an atypical centriole, it does not form a dominant sperm aster and is likely discontinuous with the axoneme, or it must be cleaved prior to the first mitosis, as was proposed in Xenopus (Fechter et al. 1996). Instead of centrioles, the microtubule bridges resulting from embryonic divisions seem to be the dominant microtubule-organizing centers (Zenker et al. 2017). Despite that, the mouse sperm tail is maintained up to the 16- to 32-cell stage (Simerly et al. 1993). Typical centrioles that act as microtubule-organizing centers appear in mice only at the blastula stage in an undescribed, presumably de novo, mechanism (Gueth-Hallonet et al. 1993, Coelho et al. 2013, Bangs et al. 2015).

While the data supporting typical centrioles appearing suddenly in rodent blastulas is significant, this idea that the centriole forms de novo is predominantly based on negative results and the de novo mechanism of centriole formation in the embryo is unknown. Also, studies on de novo centriole formation in tissue culture showed uncontrolled centriole number, which results in abnormal cell division (La Terra et al. 2005, Wang et al. 2015). Therefore, it is not clear how the correct number of centrioles is formed during rodent embryogenesis. Additionally, experiments in which a mouse sperm was injected into a cat egg resulted in a dominant sperm aster, as would be expected if the mouse sperm contained functional centrioles 
(Comizzoli et al. 2006, Jin et al. 2012). This finding suggests that centriole's ability to form a centrosome and an aster in the zygote is determined by a maternal program, independent of the competency of the centrioles to organize microtubules. This idea is supported by experiments in which a cat sperm was injected into a mouse egg ( $\mathrm{Xu}$ et al. 2011). In this study, the spindle appears barrel shaped (see Fig. 3 in that paper) regardless of the species of sperm injected, suggesting that the mouse egg's maternal program suppresses the formation of the sperm aster, independent of the presence of sperm centrioles. Together, these two cross-species fertilization studies lay the framework to suggest that in mice, the oocyte program that silences the centriole during meiosis continues to function in the early zygote. Indeed, it was proposed that mice show a gradual transition from the meiotic barrel-shaped spindle (observed in the oocyte) to a mitotic pointy spindle (observed in somatic cells) over several cell divisions (Courtois et al. 2012, Zenker et al. 2017). Perhaps then, the extension of the oocyte's centriole independence provided evolutionary flexibility, which ultimately resulted in an extensive centrosome reduction program in rodent sperm.

Alternatively, one can speculate that mouse sperm contains a highly remodeled, unrecognizable centriole precursor. A similar idea was proposed in the amoeba Naegleria pringsheimi. In this single cell protist, centrioles were also thought to form de novo (FritzLaylin \& Fulton 2016), but recently, a new model was suggested based on an atypical centriole precursor (Lee et al. 2014, 2015). Naegleria has two forms: an amoeba and flagellate. The amoeba form undergoes mitosis and lacks recognizable centrioles. The flagellate is a differentiated and non-dividing form that has two centrioles (basal bodies) that appear during differentiation. These studies from the Lee lab suggest that the centrioles form from a preexisting centriole precursor, which bears no resemblance to a typical centriole. This precursor duplicates in the amoeba, thus explaining how a precise number of centrioles can be inherited without the preexisting typical centrioles. This model of inheritance in Naegleria is currently controversial, but it provides an alternative framework to study centriole inheritance in a system that lacks recognizable centrioles, such as mice.

In conclusion, the de novo model is currently widely accepted for rodent centriole inheritance, but it is worth noting that alternative explanations exist. The idea that rodent sperm may lack centrioles challenges the idea that centrioles are essential for microtubule organization during fertilization and early development. However, the role and implications of the human atypical centriole in maintaining centriole number during embryogenesis should not be overlooked since it is possible that rodents also possess atypical centrioles that maintain a precise centriole number.

\section{What is the function of the remodeled centriole?}

To form a developmentally competent zygote, a sperm must swim faster than other male's sperm and fertilize the oocyte, and, together with the ooctye, form a functional cell. Therefore, a logical hypothesis is that the remodeled sperm centrosome may have a role in one or more of these functions. In the spermatozoa, it was proposed that the remodeled DC functions as a transitional connecting centriole,' establishing continuity between the axoneme and the PC (Zamboni \& Stefanini 1971). In this model, the PC is the 'basal body of the flagellum and the center of the sperm motility'. However, this model does not clarify the role of DC remodeling and how the remodeling helps in motility.

An insight into the function of the remodeled centriole may be gained from tracking the global change in sperm organization during evolution. It appears that flagellum symmetry correlates with fertilization types. In animals that use external fertilization, the flagellum has mostly radial symmetry (nine-fold symmetry). The only structure that does not have nine-fold symmetry is the central pair of microtubules found in the axoneme's central apparatus. This central pair is fixed in place relative to the axoneme and is important to generate planar movement (Ishijima et al. 1988, Nicastro et al. 2005, Gadelha et al. 2006). However, in animals with internal fertilization, the flagellum has increased bilateral symmetry (two-fold symmetry) (Lindemann \& Lesich 2016). In addition to the presence of a central pair, the flagellum contains accessory structures, such as, fibrous sheath, outer dense fibers (ODF) and striated columns, which have bilateral symmetry. For example, the ODF exhibits bilateral symmetry because although there are nine lobes of electron-dense material, the third and eighth lobes are larger than the others. As a result, the overall structure of the mammalian connecting piece appears flattened within the plane of the flagellar beat (Ounjai et al. 2012). The accessory structures are believed to be passive elastic elements that influence the degree of flexibility, the plane of flagellar motion and the shape of the flagellar beat (Eddy et al. 2003, Lindemann \& Lesich 2016). Importantly, the remodeled DC also appears to exhibit bilateral symmetry. This bilateral symmetry throughout the sperm tail, and particularly in the DC, may enhance the sperm's planar movement that may be suitable for navigating a complex environment such as the female reproductive tract.

In the zygote, the remodeled DC functions as a centriole, recruiting maternal PCM proteins, reconstituting a centrosome that forms an aster, and participating in spindle pole formation (Fig. 5). Also, the remodeled DC serves as a platform for the formation of a new centriole. These are normal centriolar functions, despite the DC's atypical appearance. But, the advantage of having an atypical centriole in the zygote is not clear. Studies in the fly suggest that centrosome remodeling is 

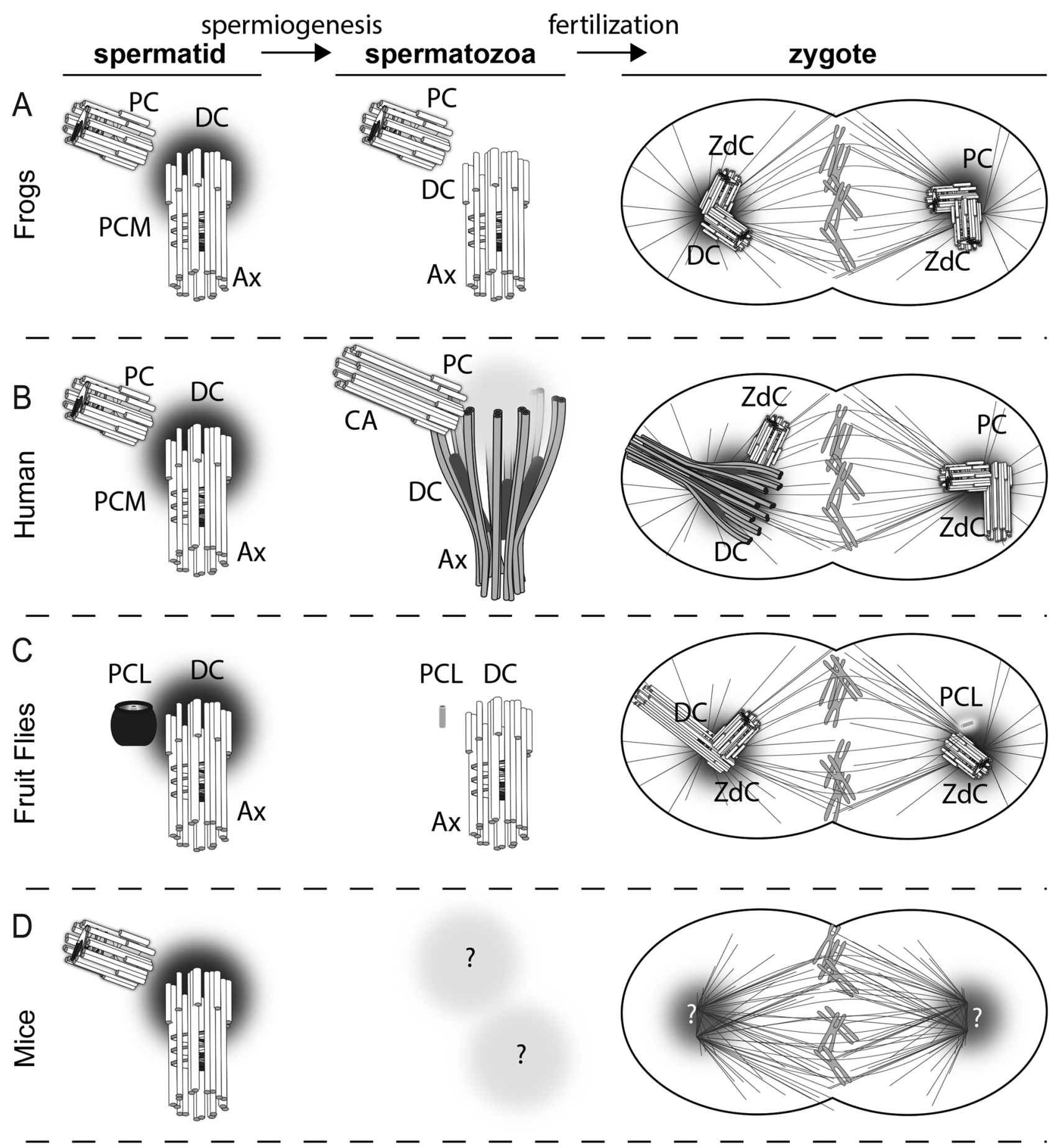

Figure 5 Models of centriole inheritance in various animal species. Model of sperm centriole inheritance in (A) frogs, (B) human, (C) flies and (D) mice. Ax, axoneme; Ca, centriole adjunct; DC, distal centriole; PC, proximal centriole; PCL, proximal centriole-like structure; ZdC, zygotic daughter centriole.

essential for centrosome reconstitution, aster formation, normal fertility and normal embryo development, but did not point out the specific benefit (Khire et al. 2015). In mammals, one potential role of the atypical centriole is providing a signal for differential fates of the zygote's daughter cells; however, this has not yet been tested.
Therefore, an important future direction is to understand the role of the centriole remodeling in the zygote.

The first function of the sperm centrioles in the zygote is to reconstitute the centrosome that produces the large sperm aster. Astral microtubules are nucleated by $\gamma$-tubulin complexes (Kollman et al. 2011). Therefore, it is interesting 
that the sperm centrioles lose their $\gamma$-tubulin complexes during centrosome reduction. One explanation may be that the biology of the spermatozoon and the zygote are so distinct that to better execute their specialized functions, they use different isoforms of the same protein. One way to replace the sperm-specific isoform with a zygote-specific isoform is by removing it during sperm centrosome remodeling and recruiting the proper isoform from the egg cytoplasm. In support of this idea, it was reported that during spermatogenesis, the fly expresses only the $\gamma$-tubulin isoform Tub23C. Then, the egg switches to expressing the Tub37CD isoform that continues to be present in early embryogenesis (Wilson et al. 1997).

In addition to the differences in the number, structure and composition of the gamete centrioles, the zygote deviates from classic centriole biology. Shortly after the sperm fuses with the egg (syngamy) (Fig. 6A), the sperm centrioles recruit maternal PCM proteins to reconstitute a centrosome (Fig. 6B) before the centrioles duplicate (Fig. 6C), unlike in a classic cell cycle when the PCM is recruited to the centriole after procentriole formation, as part of centrosome maturation (Schatten 1994). The reconstituted centrosome that is found near the male pronucleus forms a large aster, known as the sperm aster (Longo \& Anderson 1968); this is different from the classic cell cycle in which the mother centriole forms a cilium at this stage (Sanchez \& Dynlacht 2016). In parallel to PCM recruitment and sperm aster formation, the egg that is arrested in metaphase of meiosis II, restarts meiosis and generates a new polar body and the female pronucleus. Having an acentriolar spindle dividing the female chromosomes while the centriole forms the sperm aster is a situation unique to the zygote and is not found in the normal cell cycle. Once the
A
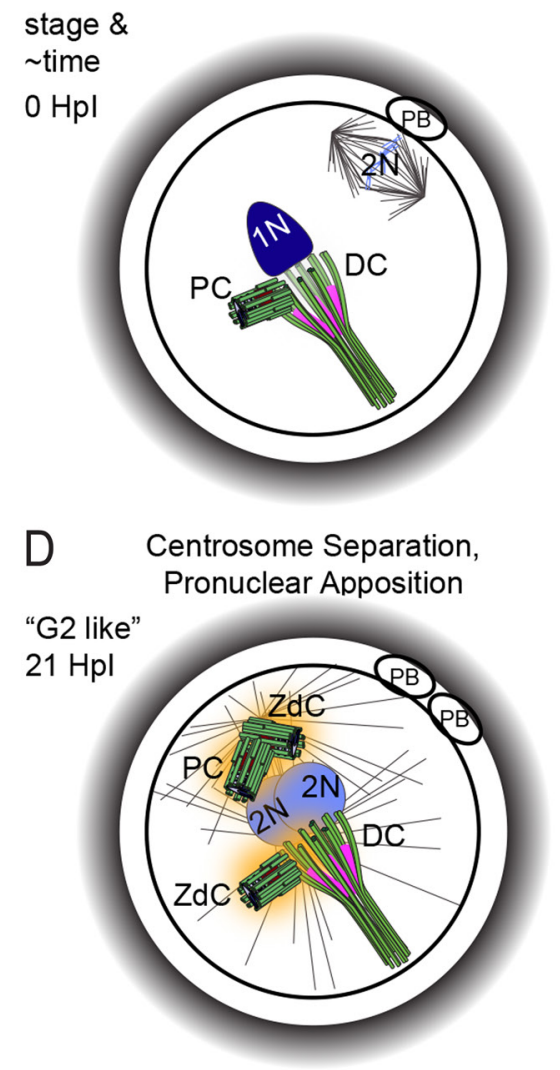

B

Centrosome Reconstitution, $2^{\text {nd }}$ Polar Body extrusion

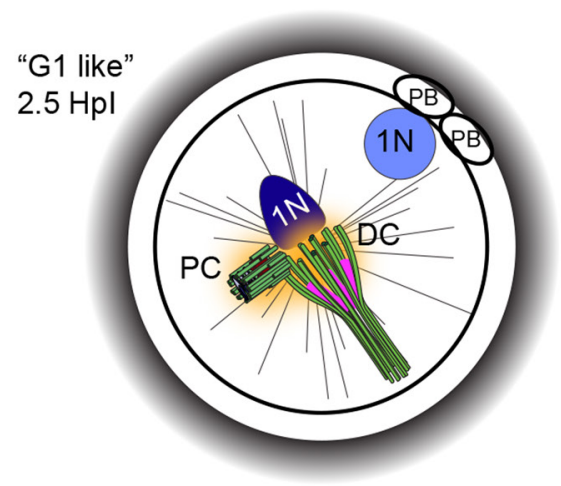

E

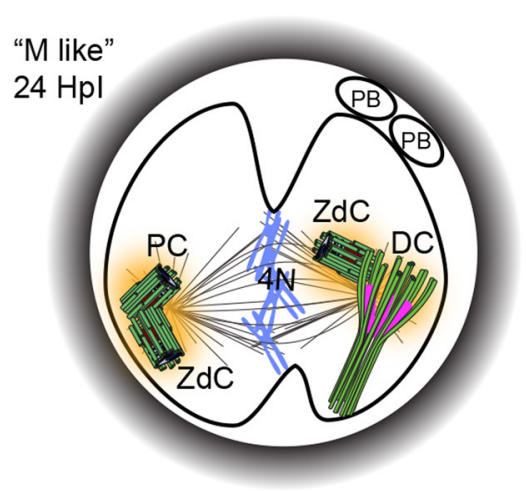
C DNA duplication, Sperm Pronucleus Decondensation

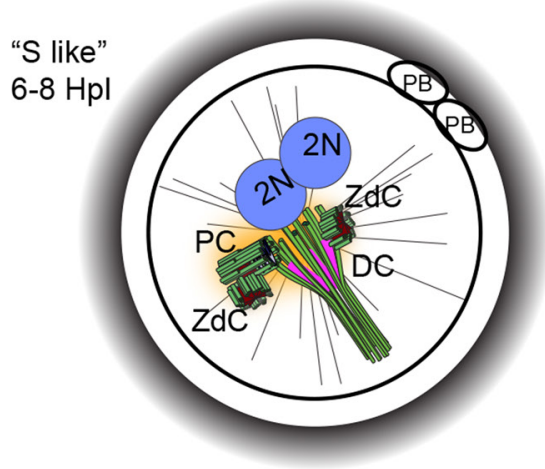

F 2 Blastomeres

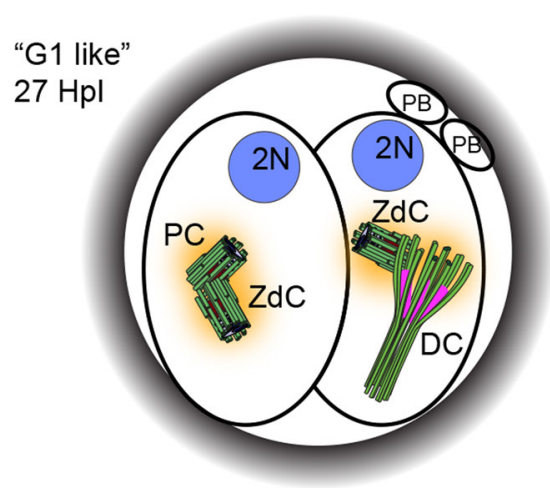

Figure 6 The centrioles in the zygote. When the sperm fuses with the oocyte, the oocyte is arrested at meiosis II (A). Upon entry, the oocyte finishes the second meiotic division and extrudes the second polar body, while the sperm centrosome (DC and PC) is reconstituted and forms a large aster (B). Then, the maternal pronucleus migrates toward the paternal pronucleus and the centrioles begin duplication (producing two zygotic daughter centrioles), presumably while the DNA is duplicating (C). Next, the zygote centrosomes separate from each other while the pronuclei begin to merge (D). Then the zygote undergoes mitosis, much like a normal dividing cell (E), and this division results in two blastomeres (F), which will not form cilia like a normal cell in G0/G1. These two blastomeres will alternate between M and S phases; they will not form cilia or exhibit cytoplasmic growth until the blastocyst stage (Artus et al. 2006). The timing of the events in approximate hours post insemination and the similar phase (stage) in regular cell cycles are indicated and timing approximations are based on (Mio \& Maeda 2008). The exact timing of centriole duplication is unknown; this drawing is based on parsimony and assumptions based on normal centriole duplication. $1 \mathrm{~N}, 2 \mathrm{~N}, 4 \mathrm{~N}$, chromosome ploidy; DC, distal centriole; PB, polar body; PC, proximal centriole; ZdC, zygotic daughter centriole. 
sperm aster and female pronucleus are formed, the sperm aster facilitates the migration of the female and male pronuclei toward each other to allow karyogamy. This migration is thought to be mediated by cytoplasmic dynein motors that are attached to the pronuclei (Payne et al. 2003, Meyerzon et al. 2009, Tanimoto et al. 2016, Tanimoto et al. 2018).

Later in zygote development, around the time the two pronuclei are in apposition, the zygote enters an $\mathrm{S}$ phase-like state where chromosomes duplicate (Fig. 6C). At that time, each of the two sperm centrioles nucleate a new procentriole. Around that time, the two pairs of centrioles separate, each forming a centrosome with an aster. This separation is like a ' $\mathrm{G} 2^{\prime}$ ' phase in a dividing somatic cell (Fig. 6D).

Next, similar to ' $\mathrm{M}$ ' phase, each centrosome localizes to a spindle pole in non-rodent mammals (Fig. 6E). One interesting difference from dividing somatic cells is that at metaphase, the asters in the poles are very small and they grow large during anaphase and telophase (Navara et al. 1994, Simerly et al. 1995a, Kim et al. 1996, Wu et al. 1996). The difference in aster size at different stages of human zygotic mitosis may be explained by a recent paper that suggested that mouse zygote mitosis starts with two spindles (Reichmann et al. 2018). It was found that mouse zygotes have both a male and a female spindle that function separately up until metaphase. During anaphase, the two spindles align, forming one spindle, where the paternal and maternal chromosomes are found in distinct groups (Fig. 5D). However, since the mouse's barrel-shaped spindle is so visually different than the pointy spindle of humans, it is possible that this two-spindle arrangement is unique to rodents. It has been proposed that the lack of recognizable centrioles in mice may be implicated in this two-spindle zygotic division, and therefore, it would be important to test if a two align spindles occurs in non-rodents zygotes that possess sperm centrioles (Zielinska \& Schuh 2018). Interestingly, insects also keep the paternal and maternal genetic material separate during zygotic metaphase (Tram et al. 2002, Snook et al. 2011).

Finally, once the zygote divides, it gives rise to two daughter cells (blastomeres), which resume the canonical cell division cycle (Fig. 6F). Altogether, the zygote has many unique centriolar characteristics. It leaves an open question as to if atypical centrioles are an adaptation needed for the unique characteristics of the zygote or if they are an outcome of evolutionary pressure to make more efficient motile spermatozoa.

\section{Concluding remarks}

The discovery of an atypical centriole in the sperm of human and other non-rodent mammals begins to resolve a debate on centrioles in reproductive biology that has spanned decades. However, how rodents get their first embryonic centriole is still an enigma. This finding necessitates new experimental and clinical adaptations. Basic researchers should address how atypical centrioles form and function, how the function of the two centrioles is coordinated and how both eventually form a typical centrosome. Evidence in animal studies suggests that the atypical centriole may be important for sperm motility and early embryonic development, but direct findings in humans are limited.

The discovery of the atypical centriole has several potential clinical implications:

(i) A defect in the centrosome remodeling process could potentially be a new cause of reproductive diseases such as idiopathic infertility, early pregnancy loss and embryo development defects. Therefore, studies of the correlation between atypical centriole abnormalities and these conditions are needed.

(ii) Some currently used treatments or procedures of male infertility (e.g., intracytoplasmic sperm injection (ICSI)) may, unknowingly, adversely affect the atypical sperm centriole. Additionally, these treatments and procedures may be insufficient to overcome defects in the atypical centriole. Therefore, studying the atypical centriole during ICSI and developing a test to diagnose abnormalities in the atypical centriole might improve ICSI success rates.

(iii) Interfering with atypical centriole formation could potentially be a target for male contraception. Therefore, identifying sperm-specific regulators of atypical centriole formation would be significant.

With all these potential roles of the atypical centriole and its implications in existing therapies, an important future research direction is to better understand the fundamental cellular processes that form the sperm's atypical centriole, as well as sperm centriole-associated reproductive diseases.

Due to the nature of this work, collaborative projects between clinicians and basic researchers are imperative to determining the impact of the atypical DC on fertility and reproduction, and also to capitalize on any findings to improve fertilization, pregnancy, healthy births and contraception. The discovery of a new sperm atypical centriole opens the door to new research directions and holds potential to lead to exciting innovative approaches in reproductive biomedicine.

\section{Declaration of interest}

The authors declare that there is no conflict of interest that could be perceived as prejudicing the impartiality of this review.

\section{Funding}

This work was supported by grant R03 HD087429 and R21 HD092700 from Eunice Kennedy Shriver National Institute of Child Health \& Human Development (NICHD). 


\section{Acknowledgements}

The authors would like to thank Katerina Turner and Sushil Khanal for assistance in preparing the manuscript.

\section{References}

Arquint C \& Nigg EA 2016 The PLK4-STIL-SAS-6 module at the core of centriole duplication. Biochemical Society Transactions 44 1253-1263. (https://doi.org/10.1042/BST20160116)

Artus J, Babinet C \& Cohen-Tannoudji M 2006 The cell cycle of early mammalian embryos: lessons from genetic mouse models. Cell Cycle 5 499-502. (https://doi.org/10.4161/cc.5.5.2500)

Avidor-Reiss T 2018 Rapid evolution of sperm produces diverse centriole structures that reveal the most rudimentary structure needed for function. Cells 7 67. (https://doi.org/10.3390/cells7070067)

Avidor-Reiss T \& Leroux MR 2015 Shared and distinct mechanisms of compartmentalized and cytosolic ciliogenesis. Current Biology 25 R1143-R1150. (https://doi.org/10.1016/j.cub.2015.11.001)

Avidor-Reiss T, Ha A \& Basiri ML 2017 Transition zone migration: a mechanism for cytoplasmic ciliogenesis and postaxonemal centriole elongation. Cold Spring Harbor Perspectives in Biology 91.

Azimzadeh J, Hergert P, Delouvee A, Euteneuer U, Formstecher E, Khodjakov A \& Bornens M 2009 hPOC5 is a centrin-binding protein required for assembly of full-length centrioles. Journal of Cell Biology 185 101-114. (https://doi.org/10.1083/jcb.200808082)

Bangs FK, Schrode N, Hadjantonakis AK \& Anderson KV 2015 Lineage specificity of primary cilia in the mouse embryo. Nature Cell Biology 17 113-122. (https://doi.org/10.1038/ncb3091)

Basiri ML, Ha A, Chadha A, Clark NM, Polyanovsky A, Cook B \& AvidorReiss T 2014 A migrating ciliary gate compartmentalizes the site of axoneme assembly in Drosophila spermatids. Current Biology 24 2622-2631. (https://doi.org/10.1016/j.cub.2014.09.047)

Blachon S, Gopalakrishnan J, Omori Y, Polyanovsky A, Church A, Nicastro D, Malicki J \& Avidor-Reiss T 2008 Drosophila asterless and vertebrate Cep152 Are orthologs essential for centriole duplication. Genetics $1802081-2094$. (https://doi.org/10.1534/genetics.108.095141)

Blachon S, Cai X, Roberts KA, Yang K, Polyanovsky A, Church A \& Avidor-Reiss T 2009 A proximal centriole-like structure is present in Drosophila spermatids and can serve as a model to study centriole duplication. Genetics 182 133-144. (https://doi.org/10.1534/ genetics.109.101709)

Blachon S, Khire A \& Avidor-Reiss T 2014 The origin of the second centriole in the zygote of Drosophila melanogaster. Genetics 197 199-205. (https://doi.org/10.1534/genetics.113.160523)

Bornens M 2012 The centrosome in cells and organisms. Science 335 422-426. (https://doi.org/10.1126/science.1209037)

Bornens M \& Azimzadeh J 2007 Origin and evolution of the centrosome. Advances in Experimental Medicine and Biology 607 119-129.

Brooks ER \& Wallingford JB 2014 Multiciliated cells. Current Biology 24 R973-R982. (https://doi.org/10.1016/j.cub.2014.08.047)

Calarco PG 2000 Centrosome precursors in the acentriolar mouse oocyte. Microscopy Research and Technique 49 428-434. (https:// doi.org/10.1002/(SICI)1097-0029(20000601)49:5<428::AIDJEMT4>3.0.CO;2-K)

Carvalho-Santos Z, Machado P, Branco P, Tavares-Cadete F, RodriguesMartins A, Pereira-Leal JB \& Bettencourt-Dias M 2010 Stepwise evolution of the centriole-assembly pathway. Journal of Cell Science 123 1414-1426. (https://doi.org/10.1242/jcs.064931)

Cavazza T, Peset I \& Vernos I 2016 From meiosis to mitosis - the sperm centrosome defines the kinetics of spindle assembly after fertilization in Xenopus. Journal of Cell Science 129 2538-2547. (https://doi. org/10.1242/jcs.183624)

Chang CW, Hsu WB, Tsai JJ, Tang CJ \& Tang TK 2016 CEP295 interacts with microtubules and is required for centriole elongation. Journal of Cell Science 129 2501-2513. (https://doi.org/10.1242/jcs.186338)

Chapman MJ, Dolan MF \& Margulis L 2000 Centrioles and kinetosomes: form, function, and evolution. Quarterly Review of Biology 75 409-429. (https://doi.org/10.1086/393621)

Chatzimeletiou K, Morrison EE, Prapas N, Prapas Y \& Handyside AH 2008 The centrosome and early embryogenesis: clinical insights.
Reproductive BioMedicine Online 16 485-491. (https://doi.org/10.1016/ S1472-6483(10)60455-5)

Chemes HE 2012 Sperm centrioles and their dual role in flagellogenesis and cell cycle of the zygote. In The Centrosome,Ed: Schatten H pp. 33-48.

Chen C, Fingerhut JM \& Yamashita YM 2016 The ins(ide) and outs(ide) of asymmetric stem cell division. Current Opinion in Cell Biology 43 1-6. (https://doi.org/10.1016/j.ceb.2016.06.001)

Clift D \& Schuh M 2015 A three-step MTOC fragmentation mechanism facilitates bipolar spindle assembly in mouse oocytes. Nature Communications 6 7217. (https://doi.org/10.1038/ncomms8217)

Coelho PA, Bury L, Sharif B, Riparbelli MG, Fu J, Callaini G, Glover DM \& Zernicka-Goetz M 2013 Spindle formation in the mouse embryo requires Plk4 in the absence of centrioles. Developmental Cell 27 586-597. (https://doi.org/10.1016/j.devcel.2013.09.029)

Comizzoli P, Wildt DE \& Pukazhenthi BS 2006 Poor centrosomal function of cat testicular spermatozoa impairs embryo development in vitro after intracytoplasmic sperm injection. Biology of Reproduction 75 252-260. (https://doi.org/10.1095/biolreprod.106.051342)

Connolly JA, Kiosses BW \& Kalnins VI 1986 Centrioles are lost as embryonic myoblasts fuse into myotubes in vitro. European Journal of Cell Biology 39 341-345.

Courtois A, Schuh M, Ellenberg J \& Hiiragi T 2012 The transition from meiotic to mitotic spindle assembly is gradual during early mammalian development. Journal of Cell Biology 198 357-370. (https://doi. org/10.1083/jcb.201202135)

Dallai R, Paoli F, Mercati D \& Lupetti P 2016 The centriole adjunct of insects: need to update the definition. Tissue Cell 48 104-113. (https:// doi.org/10.1016/j.tice.2016.02.001)

Dallai R, Mercati D, Lino-Neto J, Dias G \& Lupetti P 2017 Evidence of a procentriole during spermiogenesis in the coccinellid insect Adalia decempunctata (L): An ultrastructural study. Arthropod Structure and Development 46 815-823. (https://doi.org/10.1016/j. asd.2017.10.004)

Debec A, Sullivan W \& Bettencourt-Dias M 2010 Centrioles: active players or passengers during mitosis? Cellular and Molecular Life Sciences 67 2173-2194. (https://doi.org/10.1007/s00018-010-0323-9)

Eddy EM, Toshimori K \& O'Brien DA 2003 Fibrous sheath of mammalian spermatozoa. Microscopy Research and Technique 61 103-115. (https:// doi.org/10.1002/jemt.10320)

Fabian L \& Brill JA 2012 Drosophila spermiogenesis: big things come from little packages. Spermatogenesis 2 197-212. (https://doi.org/10.4161/ spmg.21798)

Fawcett DW \& Phillips DM 1969 The fine structure and development of the neck region of the mammalian spermatozoon. Anatomical Record $\mathbf{1 6 5}$ 153-164. (https://doi.org/10.1002/ar.1091650204)

Fechter J, Schoneberg A \& Schatten G 1996 Excision and disassembly of sperm tail microtubules during sea urchin fertilization: requirements for microtubule dynamics. Cell Motility and the Cytoskeleton $\mathbf{3 5}$ 281-288. (https://doi.org/10.1002/(SICl)10970169(1996)35:4<281::AID-CM1>3.0.CO;2-A)

Firman RC \& Simmons LW 2010 Sperm midpiece length predicts sperm swimming velocity in house mice. Biology Letters 6 513-516. (https:// doi.org/10.1098/rsbl.2009.1027)

Fisher HS, Jacobs-Palmer E, Lassance JM \& Hoekstra HE 2016 The genetic basis and fitness consequences of sperm midpiece size in deer mice. Nature Communications 7 13652. (https://doi.org/10.1038/ ncomms13652)

Fishman EL, Jo K, Ha A, Royfman R, Zinn A, Krishnamurthy M \& AvidorReiss T 2017 Atypical centrioles are present in Tribolium sperm. Open Biology 7.

Fishman EL, Jo K, Nguyen QPH, Kong D, Royfman R, Cekic AR, Khanal S, Miller AL, Simerly C, Schatten G et al. 2018 A novel atypical sperm centriole is functional during human fertilization. Nature Communications 9 2210. (https://doi.org/10.1038/s41467-018-04678-8)

Fritz-Laylin LK \& Fulton C 2016 Naegleria: a classic model for de novo basal body assembly. Cilia 5 10. (https://doi.org/10.1186/s13630-0160032-6)

Gadelha C, Wickstead B, McKean PG \& Gull K 2006 Basal body and flagellum mutants reveal a rotational constraint of the central pair microtubules in the axonemes of trypanosomes. Journal of Cell Science 119 2405-2413. (https://doi.org/10.1242/jcs.02969) 
Garcia G 3rd\& Reiter JF 2016 A primer on the mouse basal body. Cilia $\mathbf{5}$ 17. (https://doi.org/10.1186/s13630-016-0038-0)

Gervasi MG \& Visconti PE 2016 Chang's meaning of capacitation: a molecular perspective. Molecular Reproduction and Development 83 860-874. (https://doi.org/10.1002/mrd.22663)

Gob E, Schmitt J, Benavente R \& Alsheimer M 2010 Mammalian sperm head formation involves different polarization of two novel LINC complexes. PLoS ONE 5 e12072. (https://doi.org/10.1371/journal.pone.0012072)

Godinho SA \& Pellman D 2014 Causes and consequences of centrosome abnormalities in cancer. Philosophical Transactions of the Royal Society B: Biological Sciences 369.

Gomendio M \& Roldan ER 1991 Sperm competition influences sperm size in mammals. Proceedings. Biological Sciences 243 181-185. (https://doi. org/10.1098/rspb.1991.0029)

Gomes ER, Jani S \& Gundersen GG 2005 Nuclear movement regulated by Cdc42, MRCK, myosin, and actin flow establishes MTOC polarization in migrating cells. Cell 121 451-463. (https://doi.org/10.1016/j. cell.2005.02.022)

Gordon M 1972 The distal centriole in guinea pig spermiogenesis. Journal of Ultrastructure Research 39 364-388. (https://doi.org/10.1016/S00225320(72)90029-9)

Goto M, O'Brien DA \& Eddy EM 2010 Speriolin is a novel human and mouse sperm centrosome protein. Human Reproduction 25 1884-1894. (https://doi.org/10.1093/humrep/deq138)

Gottardo M, Callaini G \& Riparbelli MG 2015 Structural characterization of procentrioles in Drosophila spermatids. Cytoskeleton 72 576-584. (https://doi.org/10.1002/cm.21260)

Graser S, Stierhof YD, Lavoie SB, Gassner OS, Lamla S, Le Clech M \& Nigg EA 2007 Cep164, a novel centriole appendage protein required for primary cilium formation. Journal of Cell Biology 179 321-330. (https:// doi.org/10.1083/jcb.200707181)

Groisman I, Huang YS, Mendez R, Cao Q, Theurkauf W \& Richter JD 2000 CPEB, maskin, and cyclin B1 mRNA at the mitotic apparatus: implications for local translational control of cell division. Cell $\mathbf{1 0 3}$ 435-447. (https://doi.org/10.1016/S0092-8674(00)00135-5)

Gueth-Hallonet C, Antony C, Aghion J, Santa-Maria A, Lajoie-Mazenc I, Wright M \& Maro B 1993 gamma-Tubulin is present in acentriolar MTOCs during early mouse development. Journal of Cell Science $\mathbf{1 0 5}$ (Pt 1) 157-166.

Guichard P, Hamel V \& Gonczy P 2018 the rise of the cartwheel: seeding the centriole organelle. Bioessays $\mathbf{4 0}$ e1700241. (https://doi.org/10.1002/ bies.201700241)

Healy JM \& Jamieson BGM 1994 The ultrastructure of spermatogenesis and epididymal spermatozoa of the tuatara Sphenodon punctatus (Sphenodontida, Amniota). Philosophical Transactions: Biological Sciences 344 187-199. (https://doi.org/10.1098/rstb.1994.0060)

Hinchcliffe EH 2014 Centrosomes and the art of mitotic spindle maintenance. International Review of Cell and Molecular Biology 313 179-217.

Hinchcliffe EH, Li C, Thompson EA, Maller JL \& Sluder G 1999 Requirement of $\mathrm{Cdk} 2$-cyclin $\mathrm{E}$ activity for repeated centrosome reproduction in Xenopus egg extracts. Science 283 851-854. (https://doi.org/10.1126/ science.283.5403.851)

Hodges ME, Scheumann N, Wickstead B, Langdale JA \& Gull K 2010 Reconstructing the evolutionary history of the centriole from protein components. Journal of Cell Science 123 1407-1413. (https://doi. org/10.1242/jcs.064873)

Houliston E \& Elinson RP 1991 Patterns of microtubule polymerization relating to cortical rotation in Xenopus laevis eggs. Development 112 107-117.

Hung LY, Tang CJ \& Tang TK 2000 Protein 4.1 R-135 interacts with a novel centrosomal protein (CPAP) which is associated with the gamma-tubulin complex. Molecular and Cellular Biology 20 7813-7825. (https://doi. org/10.1128/MCB.20.20.7813-7825.2000)

Ibrahim R, Messaoudi C, Chichon FJ, Celati C \& Marco S 2009 Electron tomography study of isolated human centrioles. Microscopy Research and Technique 72 42-48. (https://doi.org/10.1002/jemt.20637)

Inoue D, Wittbrodt J \& Gruss OJ 2018 Loss and rebirth of the animal microtubule organizing center: how maternal expression of centrosomal proteins cooperates with the sperm centriole in zygotic centrosome reformation. Bioessays $\mathbf{4 0}$ e1700135. (https://doi.org/10.1002/ bies.201700135)
Ishijima S, Sekiguchi K \& Hiramoto Y 1988 Comparative study of the beat patterns of american and asian horseshoe crab sperm: evidence for a role of the central pair complex in forming planar waveforms in flagella. Cell Motility 9 264-270. (https://doi.org/10.1002/ cm.970090308)

Iwashita T \& Oura C 1980 A three dimensional analysis of the capitellum and striated columns in the sperm neck region of the mouse. Okajimas Folia Anatomica Japonica 56 361-382. (https://doi.org/10.2535/ ofaj1936.56.6_361)

Izquierdo D, Wang WJ, Uryu K \& Tsou MF 2014 Stabilization of cartwheel-less centrioles for duplication requires CEP295-mediated centriole-to-centrosome conversion. Cell Reports 8 957-965. (https:// doi.org/10.1016/j.celrep.2014.07.022)

Jamieson BG 2014 The ultrastructure of spermatogenesis and epididymal spermatozoa of the Tuatara Sphenodon punctatus. In Reproductive Biology and Phylogeny of Lizards and Tuatara, pp. 647-676.

Jin YX, Cui XS, Yu XF, Lee SH, Wang QL, Gao WW, Xu YN, Sun SC, Kong IK \& Kim NH 2012 Cat fertilization by mouse sperm injection. Zygote 20 371-378. (https://doi.org/10.1017/S0967199411000451)

Kai Y, Iwata K, Iba Y \& Mio Y 2015 Diagnosis of abnormal human fertilization status based on pronuclear origin and/or centrosome number. Journal of Assisted Reproduction and Genetics 32 1589-1595. (https://doi.org/10.1007/s10815-015-0568-1)

Keller LC, Geimer S, Romijn E, Yates J, 3rd, Zamora I \& Marshall WF 2009 Molecular architecture of the centriole proteome: the conserved WD40 domain protein POC1 is required for centriole duplication and length control. Molecular Biology of the Cell 20 1150-1166. (https://doi. org/10.1091/mbc.e08-06-0619)

Khire A, Vizuet AA, Davila E \& Avidor-Reiss T 2015 Asterless reduction during spermiogenesis is regulated by Plk4 and is essential for zygote development in Drosophila. Current Biology 25 2956-2963. (https://doi. org/10.1016/j.cub.2015.09.045)

Khire A, Jo KH, Kong D, Akhshi T, Blachon S, Cekic AR, Hynek S, Ha A, Loncarek J, Mennella V et al. 2016 Centriole remodeling during spermiogenesis in Drosophila. Current Biology 26 3183-3189. (https:// doi.org/10.1016/j.cub.2016.07.006)

Kim NH, Simerly C, Funahashi H, Schatten G \& Day BN 1996 Microtubule organization in porcine oocytes during fertilization and parthenogenesis. Biology of Reproduction 54 1397-1404. (https://doi.org/10.1095/ biolreprod54.6.1397)

Kim HK, Kang JG, Yumura S, Walsh CJ, Cho JW \& Lee J 2005 De novo formation of basal bodies in Naegleria gruberi: regulation by phosphorylation. Journal of Cell Biology 169 719-724. (https://doi. org/10.1083/jcb.200410052)

Kim TS, Park JE, Shukla A, Choi S, Murugan RN, Lee JH, Ahn M, Rhee K, Bang JK, Kim BY et al. 2013 Hierarchical recruitment of Plk4 and regulation of centriole biogenesis by two centrosomal scaffolds, Cep192 and Cep152. PNAS 110 E4849-E4857. (https://doi.org/10.1073/ pnas.1319656110)

Kollman JM, Merdes A, Mourey L \& Agard DA 2011 Microtubule nucleation by gamma-tubulin complexes. Nature Reviews Molecular Cell Biology 12 709-721. (https://doi.org/10.1038/nrm3209)

Kracklauer MP, Wiora HM, Deery WJ, Chen X, Bolival B Jr, Romanowicz D, Simonette RA, Fuller MT, Fischer JA \& Beckingham KM 2010 The Drosophila SUN protein Spag4 cooperates with the coiled-coil protein Yuri Gagarin to maintain association of the basal body and spermatid nucleus. Journal of Cell Science 123 2763-2772. (https://doi. org/10.1242/jcs.066589)

Kracklauer MP, Link J \& Alsheimer M 2013 LINCing the nuclear envelope to gametogenesis. Current Topics in Developmental Biology 102 127-157.

Kratz AS, Barenz F, Richter KT \& Hoffmann I 2015 Plk4-dependent phosphorylation of STIL is required for centriole duplication. Biology Open 4 370-377. (https://doi.org/10.1242/bio.201411023)

La Terra S, English CN, Hergert P, McEwen BF, Sluder G \& Khodjakov A 2005 The de novo centriole assembly pathway in HeLa cells: cell cycle progression and centriole assembly/maturation. Journal of Cell Biology 168 713-722. (https://doi.org/10.1083/jcb.200411126)

Lecuyer E, Yoshida H, Parthasarathy N, Alm C, Babak T, Cerovina T, Hughes TR, Tomancak P \& Krause HM 2007 Global analysis of mRNA localization reveals a prominent role in organizing cellular architecture and function. Cell 131 174-187. (https://doi.org/10.1016/j. cell.2007.08.003) 
Lee J, Kang S, Choi YS, Kim H, Yeo C, Lee Y, Roth J \& Lee J 2014 Identification of a cell cycle-dependent duplicating complex that assembles basal bodies de novo in Naegleria. Protist 166 1-13. (https:// doi.org/10.1016/j.protis.2014.11.001)

Lee J, Kang S, Choi YS, Kim HK, Yeo CY, Lee Y, Roth J \& Lee J 2015 Identification of a cell cycle-dependent duplicating complex that assembles basal bodies de novo in Naegleria. Protist 166 1-13. (https:// doi.org/10.1016/j.protis.2014.11.001)

Lehti MS \& Sironen A 2016 Formation and function of the manchette and flagellum during spermatogenesis. Reproduction 151 R43-R54. (https:// doi.org/10.1530/REP-15-0310)

Lerit DA, Smyth JT \& Rusan NM 2013 Organelle asymmetry for proper fitness, function, and fate. Chromosome Research 21 271-286. (https:// doi.org/10.1007/s10577-013-9350-3)

Lin YC, Chang CW, Hsu WB, Tang CJ, Lin YN, Chou EJ, Wu CT \& Tang TK 2013 Human microcephaly protein CEP135 binds to hSAS- 6 and CPAP, and is required for centriole assembly. EMBO Journal 32 1141-1154. (https://doi.org/10.1038/emboj.2013.56)

Lindemann CB \& Lesich KA 2016 Functional anatomy of the mammalian sperm flagellum. Cytoskeleton 73 652-669. (https://doi.org/10.1002/ cm.21338)

Liska F, Gosele C, Rivkin E, Tres L, Cardoso MC, Domaing P, Krejci E, Snajdr P, Lee-Kirsch MA, de Rooij DG et al. 2009 Rat hd mutation reveals an essential role of centrobin in spermatid head shaping and assembly of the head-tail coupling apparatus. Biology of Reproduction 81 1196-1205. (https://doi.org/10.1095/biolreprod.109.078980)

Longo FJ \& Anderson E 1968 The fine structure of pronuclear development and fusion in the sea urchin, Arbacia punctulata. Journal of Cell Biology 39 339-368. (https://doi.org/10.1083/jcb.39.2.339)

Loppin B, Dubruille R \& Horard B 2015 The intimate genetics of Drosophila fertilization. Open Biology 5 150076. (https://doi.org/10.1098/ rsob.150076)

Loukil A, Tormanen K \& Sutterlin C 2017 The daughter centriole controls ciliogenesis by regulating Neurl-4 localization at the centrosome. Journal of Cell Biology 216 1287-1300. (https://doi.org/10.1083/ jcb.201608119)

Lupold S \& Pitnick S 2018 Sperm form and function: what do we know about the role of sexual selection? Reproduction 155 R229-R243. (https://doi.org/10.1530/REP-17-0536)

Malicki J \& Avidor-Reiss T 2014 From the cytoplasm into the cilium: bon voyage. Organogenesis 10 138-157. (https://doi.org/10.4161/org.29055)

Manandhar G \& Schatten G 2000 Centrosome reduction during Rhesus spermiogenesis: gamma-tubulin, centrin, and centriole degeneration. Molecular Reproduction and Development 56 502-511. (https://doi. org/10.1002/1098-2795(200008)56:4<502::AID-MRD8>3.0.CO;2-Q)

Manandhar G, Sutovsky P, Joshi HC, Stearns T \& Schatten G 1998 Centrosome reduction during mouse spermiogenesis. Developmental Biology 203 424-434. (https://doi.org/10.1006/dbio.1998.8947)

Manandhar G, Simerly C, Salisbury JL \& Schatten G 1999 Centriole and centrin degeneration during mouse spermiogenesis. Cell Motility and the Cytoskeleton 43 137-144. (https://doi.org/10.1002/(SICl)10970169(1999)43:2<137::AID-CM5>3.0.CO;2-7)

Manandhar G, Schatten H \& Sutovsky P 2005 Centrosome reduction during gametogenesis and its significance. Biology of Reproduction $\mathbf{7 2}$ 2-13. (https://doi.org/10.1095/biolreprod.104.031245)

Maniswami RR, Prashanth S, Karanth AV, Koushik S, Govindaraj H, Mullangi R, Rajagopal S \& Jegatheesan SK 2018 PLK4: a link between centriole biogenesis and cancer. Expert Opinion on Therapeutic Targets 22 59-73. (https://doi.org/10.1080/14728222.2018.1410140)

Marshall WF \& Rosenbaum JL 1999 Are there nucleic acids in the centrosome? In Current Topics in Developmental Biology, Eds: J L Rheubert, D S Siegel and ET S pp. 187-205.

Mazo G, Soplop N, Wang WJ, Uryu K \& Tsou MB 2016 Spatial control of primary ciliogenesis by subdistal appendages alters sensation-associated properties of cilia. Developmental Cell 39 424-437. (https://doi. org/10.1016/j.devcel.2016.10.006)

Mennella V, Agard DA, Huang B \& Pelletier L 2014 Amorphous no more: subdiffraction view of the pericentriolar material architecture. Trends in Cell Biology 24 188-197. (https://doi.org/10.1016/j.tcb.2013.10.001)

Meraldi P, Lukas J, Fry AM, Bartek J \& Nigg EA 1999 Centrosome duplication in mammalian somatic cells requires E2 F and Cdk2-cyclin A. Nature Cell Biology 1 88-93. (https://doi.org/10.1038/10054)
Meunier S \& Vernos I 2016 Acentrosomal Microtubule Assembly in Mitosis: The Where, When, and How. Trends in Cell Biology 26 80-87. (https://doi.org/10.1016/j.tcb.2015.09.001)

Meyerzon M, Gao Z, Liu J, Wu JC, Malone CJ \& Starr DA 2009 Centrosome attachment to the $\mathrm{C}$. elegans male pronucleus is dependent on the surface area of the nuclear envelope. Developmental Biology 327 433-446. (https://doi.org/10.1016/j.ydbio.2008.12.030)

Mio Y \& Maeda K 2008 Time-lapse cinematography of dynamic changes occurring during in vitro development of human embryos. American Journal of Obstetrics and Gynecology 199 660.e661-665.e661.

Mortimer D 2018 The functional anatomy of the human spermatozoon: relating ultrastructure and function. Molecular Human Reproduction 24 567-592

Mottier-Pavie V \& Megraw TL 2009 Drosophila bld10 is a centriolar protein that regulates centriole, basal body, and motile cilium assembly. Molecular Biology of the Cell 20 2605-2614. (https://doi.org/10.1091/ mbc.e08-11-1115)

Muller-Reichert T, Greenan G, O'Toole E \& Srayko M 2010 The elegans of spindle assembly. Cellular and Molecular Life Sciences 67 2195-2213. (https://doi.org/10.1007/s00018-010-0324-8)

Nagy ZP 2000 Sperm centriole disfunction and sperm immotility. Molecular and Cellular Endocrinology 166 59-62. (https://doi.org/10.1016/S03037207(00)00298-7)

Nakazawa Y, Hiraki M, Kamiya R \& Hirono M 2007 SAS-6 is a cartwheel protein that establishes the 9-fold symmetry of the centriole. Current Biology 17 2169-2174. (https://doi.org/10.1016/j.cub.2007.11.046)

Navara CS, First NL \& Schatten G 1994 Microtubule organization in the cow during fertilization, polyspermy, parthenogenesis, and nuclear transfer: the role of the sperm aster. Developmental Biology 162 29-40. (https://doi.org/10.1006/dbio.1994.1064)

Nicander L \& Bane A 1962 Fine structure of boar spermatozoa. Cell and Tissue Research 57 390-405.

Nicastro D, McIntosh JR \& Baumeister W 2005 3D structure of eukaryotic flagella in a quiescent state revealed by cryo-electron tomography. PNAS 102 15889-15894. (https://doi.org/10.1073/ pnas.0508274102)

Nigg EA \& Holland AJ 2018 Once and only once: mechanisms of centriole duplication and their deregulation in disease. Nature Reviews Molecular Cell Biology 19 297-312. (https://doi.org/10.1038/nrm.2017.127)

Nygaard MB, Almstrup K, Lindbaek L, Christensen ST \& Svingen T 2015 Cell context-specific expression of primary cilia in the human testis and ciliary coordination of Hedgehog signalling in mouse Leydig cells. Scientific Reports 5 10364. (https://doi.org/10.1038/srep10364)

O'Donnell L \& O'Bryan MK 2014 Microtubules and spermatogenesis. Seminars in Cell and Developmental Biology 30 45-54.

O'Connell KF, Caron C, Kopish KR, Hurd DD, Kemphues KJ, Li Y \& White JG 2001 The C. elegans zyg-1 gene encodes a regulator of centrosome duplication with distinct maternal and paternal roles in the embryo. Cell 105 547-558.

Ounjai P, Kim KD, Lishko PV \& Downing KH 2012 Three-dimensional structure of the bovine sperm connecting piece revealed by electron cryotomography. Biology of Reproduction 87 73. (https://doi. org/10.1093/biolreprod/87.s1.73)

Paintrand M, Moudjou M, Delacroix H \& Bornens M 1992 Centrosome organization and centriole architecture: their sensitivity to divalent cations. Journal of Structural Biology 108 107-128. (https://doi. org/10.1016/1047-8477(92)90011-X)

Palazzo RE, Vogel JM, Schnackenberg BJ, Hull DR \& Wu X 2000 Centrosome maturation. Current Topics in Developmental Biology $\mathbf{4 9}$ 449-470.

Palermo GD, Colombero LT \& Rosenwaks Z 1997 The human sperm centrosome is responsible for normal syngamy and early embryonic development. Reviews of Reproduction 2 19-27. (https://doi. org/10.1530/ror.0.0020019)

Patrick J, Comizzoli P \& Elliott G 2017 Dry Preservation of Spermatozoa: Considerations for Different Species. Biopreservation and Biobanking 15 158-168. (https://doi.org/10.1089/bio.2016.0087)

Payne C, Rawe V, Ramalho-Santos J, Simerly C \& Schatten G 2003 Preferentially localized dynein and perinuclear dynactin associate with nuclear pore complex proteins to mediate genomic union during mammalian fertilization. Journal of Cell Science 116 4727-4738. (https:// doi.org/10.1242/jcs.00784) 
Pearson CG, Osborn DP, Giddings TH Jr, Beales PL \& Winey M 2009 Basal body stability and ciliogenesis requires the conserved component Poc1. Journal of Cell Biology 187 905-920. (https://doi.org/10.1083/ jcb.200908019)

Pimenta-Marques A, Bento I, Lopes CA, Duarte P, Jana SC \& BettencourtDias M 2016 A mechanism for the elimination of the female gamete centrosome in Drosophila melanogaster. Science $\mathbf{3 5 3}$ aaf4866. (https:// doi.org/10.1126/science.aaf4866)

Rattner JB 1972 Observations of centriole formation in male meiosis. Journal of Cell Biology 54 20-29. (https://doi.org/10.1083/jcb.54.1.20)

Reichmann J, Nijmeijer B, Hossain MJ, Eguren M, Schneider I, Politi AZ, Roberti MJ, Hufnagel L, Hiiragi T \& Ellenberg J 2018 Dual-spindle formation in zygotes keeps parental genomes apart in early mammalian embryos. Science 361 189-193. (https://doi.org/10.1126/science. aar7462)

Riparbelli MG \& Callaini G 2010 Detachment of the basal body from the sperm tail is not required to organize functional centrosomes during Drosophila embryogenesis. Cytoskeleton 67 251-258.

Riparbelli MG, Dallai R \& Callaini G 2010 The insect centriole: A land of discovery. Tissue Cell 42 69-80. (https://doi.org/10.1016/j. tice.2010.01.002)

Riparbelli MG, Callaini G \& Megraw TL 2012 Assembly and persistence of primary cilia in dividing Drosophila spermatocytes. Developmental Cell 23 425-432. (https://doi.org/10.1016/j.devcel.2012.05.024)

Roosing S, Lamers IJ, de Vrieze E, van den Born LI, Lambertus S, Arts HH, Group PBS, Peters TA, Hoyng CB, Kremer H et al. 2014 Disruption of the basal body protein POC1B results in autosomal-recessive cone-rod dystrophy. American Journal of Human Genetics 95 131-142. (https:// doi.org/10.1016/j.ajhg.2014.06.012)

Ross L \& Normark BB 2015 Evolutionary problems in centrosome and centriole biology. Journal of Evolutionary Biology 28 995-1004. (https:// doi.org/10.1111/jeb.12620)

Salisbury JL, Suino KM, Busby R \& Springett M 2002 Centrin-2 is required for centriole duplication in mammalian cells. Current Biology 12 1287-1292. (https://doi.org/10.1016/S0960-9822(02)01019-9)

Sanchez I \& Dynlacht BD 2016 Cilium assembly and disassembly. Nature Cell Biology 18 711-717. (https://doi.org/10.1038/ncb3370)

Sathananthan AH, Kola I, Osborne J, Trounson A, Ng SC, Bongso A \& Ratnam SS 1991 Centrioles in the beginning of human development. PNAS 88 4806-4810. (https://doi.org/10.1073/pnas.88.11.4806)

Sathananthan AH, Ratnasooriya WD, de Silva PK \& Menezes J 2001 Characterization of human gamete centrosomes for assisted reproduction. Italian Journal of Anatomy and Embryology 106 61-73.

Schatten G 1994 The centrosome and its mode of inheritance: the reduction of the centrosome during gametogenesis and its restoration during fertilization. Developmental Biology 165 299-335. (https://doi. org/10.1006/dbio.1994.1256)

Schatten H 2012 The Centrosome: Cell and Molecular Mechanisms of Functions and Dysfunctions in Disease: Totowa, NJ, USA: Humana Press.

Schatten H \& Sun QY 2011 New insights into the role of centrosomes in mammalian fertilization and implications for ART. Reproduction 142 793-801. (https://doi.org/10.1530/REP-11-0261)

Schatten G, Simerly C \& Schatten H 1985 Microtubule configurations during fertilization, mitosis, and early development in the mouse and the requirement for egg microtubule-mediated motility during mammalian fertilization. PNAS 82 4152-4156. (https://doi.org/10.1073/ pnas.82.12.4152)

Schatten H, Schatten G, Mazia D, Balczon R \& Simerly C 1986 Behavior of centrosomes during fertilization and cell division in mouse oocytes and in sea urchin eggs. PNAS 83 105-109. (https://doi.org/10.1073/ pnas.83.1.105)

Schwarz A, Sankaralingam P, O'Connell KF \& Muller-Reichert T 2018 Revisiting centrioles in nematodes-historic findings and current topics. Cells 7 101. (https://doi.org/10.3390/cells7080101)

Severson AF, von Dassow G \& Bowerman B 2016 Oocyte Meiotic Spindle Assembly and Function. Current Topics in Developmental Biology $\mathbf{1 1 6}$ 65-98.

Shang Y, Zhu F, Wang L, Ouyang YC, Dong MZ, Liu C, Zhao H, Cui X, Ma D, Zhang Z et al. 2017 Essential role for SUN5 in anchoring sperm head to the tail. Elife 6 e28199. (https://doi.org/10.7554/eLife.28199)

Shao X, Tarnasky HA, Lee JP, Oko R \& van der Hoorn FA 1999 Spag4, a novel sperm protein, binds outer dense-fiber protein Odf1 and localizes to microtubules of manchette and axoneme. Developmental Biology 211 109-123. (https://doi.org/10.1006/dbio.1999.9297)

Shukla A, Kong D, Sharma M, Magidson V \& Loncarek J 2015 Plk1 relieves centriole block to reduplication by promoting daughter centriole maturation. Nature Communications 6 8077. (https://doi.org/10.1038/ ncomms9077)

Sillibourne JE, Hurbain I, Grand-Perret T, Goud B, Tran P \& Bornens M 2013 Primary ciliogenesis requires the distal appendage component Cep123. Biology Open 2 535-545. (https://doi.org/10.1242/ bio.20134457)

Simerly CR, Hecht NB, Goldberg E \& Schatten G 1993 Tracing the incorporation of the sperm tail in the mouse zygote and early embryo using an anti-testicular alpha-tubulin antibody. Developmental Biology 158 536-548. (https://doi.org/10.1006/dbio.1993.1211)

Simerly C, Wu GJ, Zoran S, Ord T, Rawlins R, Jones J, Navara C, Gerrity M, Rinehart J \& Binor Z 1995a The paternal inheritance of the centrosome, the cell's microtubule-organizing center, in humans, and the implications for infertility. Nature Medicine 1 47-52. (https://doi. org/10.1038/nm0195-47)

Simerly C, Wu GJ, Zoran S, Ord T, Rawlins R, Jones J, Navara C, Gerrity M, Rinehart J, Binor Z et al. 1995b The paternal inheritance of the centrosome, the cell's microtubule-organizing center, in humans, and the implications for infertility. Nature Medicine $147-52$. (https://doi. org/10.1038/nm0195-47)

Simerly C, Castro C, Hartnett C, Lin CC, Sukhwani M, Orwig K \& Schatten G 2016 Post-testicular sperm maturation: centriole pairs, found in upper epididymis, are destroyed prior to sperm's release at ejaculation. Scientific Reports 6 31816. (https://doi.org/10.1038/ srep31816)

Sluder G 2016 Using sea urchin gametes and zygotes to investigate centrosome duplication. Cilia 5 20. (https://doi.org/10.1186/s13630016-0043-3)

Snook RR, Hosken DJ \& Karr TL 2011 The biology and evolution of polyspermy: insights from cellular and functional studies of sperm and centrosomal behavior in the fertilized egg. Reproduction 142 779-792. (https://doi.org/10.1530/REP-11-0255)

Starr DA \& Fridolfsson HN 2010 Interactions between nuclei and the cytoskeleton are mediated by SUN-KASH nuclear-envelope bridges. Annual Review of Cell and Developmental Biology 26 421-444. (https:// doi.org/10.1146/annurev-cellbio-100109-104037)

Stinchcombe JC, Randzavola LO, Angus KL, Mantell JM, Verkade P \& Griffiths GM 2015 Mother centriole distal appendages mediate centrosome docking at the immunological synapse and reveal mechanistic parallels with ciliogenesis. Current Biology 25 3239-3244. (https://doi.org/10.1016/j.cub.2015.10.028)

Sullivan R \& Mieusset R 2016 The human epididymis: its function in sperm maturation. Human Reproduction Update 22 574-587. (https://doi. org/10.1093/humupd/dmw015)

Tanimoto H, Kimura A \& Minc N 2016 Shape-motion relationships of centering microtubule asters. Journal of Cell Biology 212 777-787. (https://doi.org/10.1083/jcb.201510064)

Tanimoto H, Salle J, Dodin L \& Minc N 2018 Physical Forces Determining the Persistency and Centering Precision of Microtubule Asters. Nature Physics 14 848-854. (https://doi.org/10.1038/s41567-018-0154-4)

Thery M, Racine V, Piel M, Pepin A, Dimitrov A, Chen Y, Sibarita JB \& Bornens M 2006 Anisotropy of cell adhesive microenvironment governs cell internal organization and orientation of polarity. PNAS 103 19771-19776. (https://doi.org/10.1073/pnas.0609267103)

Toure A, Rode B, Hunnicutt GR, Escalier D \& Gacon G 2011 Septins at the annulus of mammalian sperm. Biological Chemistry 392 799-803.

Tram U, Riggs B \& Sullivan W 2002 Cleavage and gastrulation in Drosophila embryos. Encyclopedia of Life Sciences.

Tsuchiya Y, Yoshiba S, Gupta A, Watanabe K \& Kitagawa D 2016 Cep295 is a conserved scaffold protein required for generation of a bona fide mother centriole. Nature Communications 7 12567. (https://doi. org/10.1038/ncomms12567)

Uzbekov R, Garanina A \& Bressac C 2018 Centrioles without microtubules - a new morphological type of centriole. Biology Open.

Verlhac MH 2016 Mother centrioles are kicked out so that starfish zygote can grow. Journal of Cell Biology 212 759-761. (https://doi.org/10.1083/ jcb.201602053) 
Wang WJ, Acehan D, Kao CH, Jane WN, Uryu K \& Tsou MF 2015 De novo centriole formation in human cells is error-prone and does not require SAS-6 self-assembly. Elife 4 e10586. (https://doi.org/10.7554/ eLife.10586)

Werner M \& Simmons LW 2008 Insect sperm motility. Biological Reviews of the Cambridge Philosophical Society 83 191-208. (https://doi. org/10.1111/j.1469-185X.2008.00039.x)

Wilson PG, Zheng Y, Oakley CE, Oakley BR, Borisy GG \& Fuller MT 1997 Differential expression of two gamma-tubulin isoforms during gametogenesis and development in Drosophila. Developmental Biology 184 207-221. (https://doi.org/10.1006/dbio.1997.8545)

Winey M \& O'Toole E 2014 Centriole structure. Philosophical Transactions of the Royal Society B: Biological Sciences 369 20130457. (https://doi. org/10.1098/rstb.2013.0457)

Wu GJ, Simerly C, Zoran SS, Funte LR \& Schatten G 1996 Microtubule and chromatin dynamics during fertilization and early development in rhesus monkeys, and regulation by intracellular calcium ions. Biology of Reproduction 55 260-270. (https://doi.org/10.1095/ biolreprod55.2.260)

Xu YN, Cui XS, Sun SC, Jin YX \& Kim NH 2011 Cross species fertilization and development investigated by cat sperm injection into mouse oocytes. Journal of Experimental Zoology Part A: Ecological Genetics and Physiology 315 349-357. (https://doi.org/10.1002/jez.682)

Yan X, Zhao H \& Zhu X 2016 Production of Basal Bodies in bulk for dense multicilia formation. F1000Research 5 1-8.

Yuan S, Stratton CJ, Bao J, Zheng H, Bhetwal BP, Yanagimachi R \& Yan W 2015 Spata6 is required for normal assembly of the sperm connecting piece and tight head-tail conjunction. PNAS 112 E430-E439. (https:// doi.org/10.1073/pnas.1424648112)

Zach F \& Stohr H 2014 FAM161A, a novel centrosomal-ciliary protein implicated in autosomal recessive retinitis pigmentosa. Advances in Experimental Medicine and Biology 801 185-190.

Zamboni L \& Stefanini M 1971 The fine structure of the neck of mammalian spermatozoa. Anatomical Record 169 155-172. (https://doi. org/10.1002/ar.1091690203)

Zenker J, White MD, Templin RM, Parton RG, Thorn-Seshold O, Bissiere S \& Plachta N 2017 A microtubule-organizing center directing intracellular transport in the early mouse embryo. Science 357 925-928. (https://doi. org/10.1126/science.aam9335)

Zheng X, Gooi LM, Wason A, Gabriel E, Mehrjardi NZ, Yang Q, Zhang X, Debec A, Basiri ML et al. 2014 Conserved TCP domain of Sas-4/CPAP is essential for pericentriolar material tethering during centrosome biogenesis. PNAS 111 E354-E363. (https://doi.org/10.1073/ pnas.1317535111)

Zielinska AP \& Schuh M 2018 Double trouble at the beginning of life. Science 361 128-129.

Received 9 July 2018

First decision 14 August 2018

Revised manuscript received 20 November 2018

Accepted 29 November 2018 